\title{
DAS SCHICKSAL EINER BIBLIOTHEK
}

\author{
MAX NETTLAU UND AMSTERDAM*
}

Vor mehr als einem halben Jahrhundert suchte Arthur Lehning im Sommer 1924 auf der vielen so bekannten Adresse Lazarettgasse 32 den Geschichtsschreiber des Anarchismus und Biographen Michael Bakunins, den passionierten Sammler sozialistischer Literatur, den Historiker Dr Max Nettlau zum ersten Mal auf. Wie ein roter Faden wird sich Nettlau, der auch an der Wiege des Internationalen Instituts für Sozialgeschichte in Amsterdam stand, bis auf den heutigen Tag durch das Leben Lehnings ziehen.

Max Nettlau wurde am 30. April 1865 in Neuwaldegg, mitten im Wiener Wald geboren. Sein Vater, ein aus dem Kreis Preussisch-Holland gebürtiger Ostpreusse, stand dort als Hofgärtner in Diensten des Fürsten Schwarzenberg. Von ihm erbte er die grosse Liebe zur Natur. April 1887 promovierte Nettlau an der Universität Leipzig über Beiträge zur cymrischen Grammatik. Seine erste historische Arbeit, eine Studie über Joseph Déjacque, erschien Anfang 1890 in Johann Mosts Freiheit in New York. Von nun an konzentrierte sich sein Studium auf Bakunin und die Geschichte des Anarchismus. ${ }^{1}$

* Übersetzung eines bearbeiteten Beitrags, erschienen in der Festschrift zu Arthur Lehnings 80. Geburtstag: Over Buonarroti, internationale avant-gardes, Max Nettlau en het verzamelen van boeken, anarchistische ministers, de algebra van de revolutie, schilders en schrijvers, Baarn 1979, S. 317-66.

$1 \mathrm{Zu}$ seinen wichtigsten Veröffentlichungen gehören: The Life of Michael Bakounine, 3 Bde, London 1896-1900 (Reprints New York 1969 und Mailand 1971); Bakunins Werke in deutsch: Gesammelte Werke, Bd 3, Berlin 1924 (Reprint Berlin 1975), in spanisch: Obras completas, 5 Bde, Buenos Aires 1925-29; drei grosse Studien über Bakunin in Italien, Spanien und Russland im Archiv für die Geschichte des Sozialismus und der Arbeiterbewegung, Jg. 2 (1912), 4 (1914) und 5 (1915); Der Vorfrühling der Anarchie. Ihre historische Entwicklung von den Anfängen bis zum Jahre 1864, Berlin 1925; Der Anarchismus von Proudhon zu Kropotkin. Seine historische Entwicklung in den Jahren 1859-1880, Berlin 1927; Anarchisten und Sozialrevolutionäre. Die historische Entwicklung des Anarchismus in den Jahren 1880-1886, Berlin 1931 (Reprint der drei Bände u.d.T. Geschichte der Anarchie, Glashütten/Ts 1972); Errico Malatesta. Das Leben eines Anarchisten, Berlin 1922 (Reprint Berlin 1973); Elisée Reclus, Anarchist und Gelehrter (1830-1905), Berlin 1928 (Reprint Glashütten/Ts 1977). 
Nettlau war ein Historiker pur sang. Sein nicht nur hervorragendes, sondern beinahe einmaliges Wissen auf dem Gebiet der sozialen Bewegungen erkannten auch marxistische Historiker wie Eduard Bernstein, Gustav Mayer, Jurij Steklov² und Boris Nikolaevskij an, der über ihn schrieb: „Mit Recht kann er ein Pionier auf dem Gebiet des Studiums der Geschichte der internationalen sozialistischen und anarchistischen Bewegungen genannt werden." 3 Seine vielen kritischen Kommentare zu Marx nahmen sie in Kauf, die Fakten konnten nicht widerlegt werden. Mit einem scharfen Blick für die allerkleinsten Details schuf Nettlau ein sowohl an Umfang wie Qualität unglaubliches, beinahe fehlerfreies Oeuvre.

Er suchte viele Militanten der frühen Bewegung auf, und ,dank dieser Kontakte mit Freunden und Bekannten Bakunins erhielt Nettlau nicht nur Informationen über die Ereignisse, sondern erwarb sich dadurch eine gründliche Kenntnis des Milieus, der Atmosphäre und der Beziehungen innerhalb der Gruppen mit all ihren Unterschieden, kurz der - wie Nettlau sich häufig ausdrückte - , intimen Geschichte', die man vergeblich in den Büchern sucht und nur in Briefen oder Erinnerungen finden kann."4

In einem Nachruf charakterisiert Lehning ihn folgendermassen:

As a person, Nettlau was very good-natured, with no social life, few material needs and no relaxations. Day in, day out, he wrote articles and books and the long letters so familiar to his friends and comrades in many countries. Rarely was a life more devoted to one purpose and a scholarly cause, with such singlemindedness and steadfastness, with such patience and complete disinterestedness. Only where authority was rejected did he discover freedom, humanity and progress. From this point of view and with an astounding knowledge of facts he wrote the history of socialism; indeed he regarded the whole development of mankind from this angle. Thus he

2 Anfang 1923 bat Steklov Nettlau um Mitarbeit bei den unter seiner Leitung im russischen Staatsverlag erscheinenden gesammelten Werken Bakunins. Nettlau lehnte jedoch $a b$, da er nicht mit einem Staat zusammenarbeiten wollte, der Anarchisten verfolgt: „Ich liebe Bakunin, aber mehr noch liebe ich meine jetzt lebenden Genossen, die Freiheit und Solidarität, und ich werde niemals etwas mit ihren Henkern zu tun haben.” Vgl. A. Lehning, ,Michael Bakunin und die Geschichtsschreibung. Ein Abriss der Bakunin-Forschung", in: Michael Bakunins sozialpolitischer Briefwechsel mit Alexander Iw. Herzen und Ogarjow, Berlin 1977, S. 19-25. Kurz nach Erscheinen des vierten Bandes seiner Bakunin-Ausgabe (1935) wurde Steklov selbst verhaftet. Er starb 1941 68-jährig in einem russischen Konzentrationslager. Nettlau kannte die anderen russischen Bakunin-Spezialisten ebenfalls persönlich: A. A. Kornilov traf er 1904 in Paris, D. Rjazanov 1907 in Wien und V. Polonskij 1922 in München.

3 B. Nikolaevskij, „Max Nettlau”, in: Socialističeskij Vestnik. Central'nyj Organ Rossijskoj Social-Demokraticeskoj Rabocej Partii (New York), 8. August 1945, S. 571.

4 Lehning, „Michael Bakunin und die Geschichtsschreibung”, a.a.O., S. 11. 
wished to make his own contribution to the story of liberty. His works and collections are a permanent and monumental source for the history of anti-authoritarian thought and libertarian socialism. ${ }^{5}$

Man müsste Nettlau, wollte man übliche Formeln benutzen, eher einen Individual- als einen Sozialanarchisten nennen. Für ihn persönlich, nicht in seinen Schriften, lagen die Möglichkeiten des Anarchismus eher in der Beeinflussung der verschiedenen sozialen und kulturellen Strömungen des gesellschaftlichen Lebens als in der Organisation der Arbeiterbewegung mit einer anarchistischen Ideologie. So sah er auch in den Krisenjahren, der Zeit der drohenden Kriegsgefahr und des aufkommenden Faschismus, mehr in einer Einheitsfront von liberal bis libertär als in einem Kampf der revolutionären Arbeiterbewegung gegen Staat und Diktatur. Nettlau „hielt viel auf die Lehre von Tolstoi, der an jeden einzelnen ethische Anforderungen stellte und diese in ihm zu erwecken suchte und bedauerte immer, dass Tolstoi durch seine religiöse Terminologie seine Werke zur Unfruchtbarkeit verurteilte." ${ }^{6}$ Seinem Freund Rudolf Rocker teilte er einst mit, er „habe an der praktischen Bewegung nie einen Anteil genommen, ausser vielleicht in meinen Artikeln, wo ich Stellung zu verschiedenen Fragen genommen habe. Mein Leben war vollständig der Geschichte der Bewegung gewidmet".?

Nettlau sah im Syndikalismus und Anarchosyndikalismus autoritäre Tendenzen. Einerseits befürchtete er, dass hieraus eine „Gewerkschaftsdiktatur" entstehen könnte, andererseits richtete sich sein Misstrauen ganz allgemein gegen den Nachdruck, den diese Bewegung statt auf die anarchistische Propaganda auf die Organisation der Arbeiter legte. Seine Kritik erscheint umso merkwürdiger, als er nicht bestreiten konnte, dass alle führenden Persönlichkeiten des Anarchosyndikalismus, meist Schüler und Mitkämpfer Kropotkins, echte Anarchisten waren, die sich auf Bakunin als den historischen und theoretischen Begründer ihrer Theorie und Praxis beriefen. Übrigens war es vor allem die deutsche

${ }^{5}$ Ders., ,Necrology of Max Nettlau”, in From Buonarroti to Bakunin, Leiden 1970, S. 20.

6 „Biographische und bibliographische Daten von Max Nettlau, März 1940”, in: International Review of Social History, Jg. 14 (1969), S. 459.

${ }^{7}$ R. Rocker, Max Nettlau. Leben und Werk des Historikers vergessener sozialer Bewegungen, Berlin 1978, S. 237-38. Dieses Buch erschien zuerst 1950 in spanischer, 1956 in schwedischer Übersetzung. Der deutsche Anarchist Rocker (1873-1958) war seit 1895 mit Nettlau befreundet. Die Verfolgung der anarchistischen Bewegung Anfang der neunziger Jahre zwang ihn, ins Ausland zu gehen, 1892 erst nach Paris, 1895 nach seiner Ausweisung nach London, wo er unter den jüdischen Arbeitern grosse Aktivitäten entwickelte. In kurzer Zeit lernte er als Nichtjude jiddisch und redigierte in dieser Sprache das anarchistische Wochenblatt Der Arbeterfraynd. Nach dem Ersten Weltkrieg kehrte er nach Deutschland zurück und baute die anarchosyndikalistische Bewegung auf. 
anarchosyndikalistische Organisation, die die wichtigsten historischen Arbeiten Nettlaus veröffentlichte.

Er war ein sonderbarer Mensch mit feinem Einfühlungsvermögen, ein Einzelgänger, der sehr parteiisch war, was er jedoch in seinen Publikationen wenig merken liess. „Im persönlichen Umgang war er freundlich, von einer gewissen Unbestimmtheit, selbst über kontroverse oder aktuelle Fragen, zu denen er sehr bestimmte Meinungen vertrat, sprach er zurückhaltend, manchmal beinahe fragend, seine Auffassung wurde dennoch sehr deutlich. Man könnte vielleicht sagen, dass sich dann seine kultivierte Wiener Art des understatement äusserte."8

In seinen Memoiren nahm er hingegen weniger ein Blatt vor den Mund als in Gesprächen, auch in einigen seiner Briefe spürt man Aggressivität gegenüber Menschen und Auffassungen, die er nicht teilen konnte. Im Grunde war er ein einsamer Mensch, der sein Leben zu einem grossen Teil mit dem Schreiben dieser oft ausführlichen Briefe und der laufenden Arbeit an seinem Geschichtswerk und später an seinen Memoiren zubrachte, einer weiteren Spiegelung seiner Auffassungen über Leben und Welt. Bakunins Freund James Guillaume, gegen den Nettlau aus persönlichen wie historischen Gründen die schärfsten, unversöhnlichsten Einwände hatte, schrieb ihm 1910: „Vous vivez dans un monde à part, le monde de vos pensées, de vos chimères, et systématiquement vous refusez de prendre contact avec la réalité. Nous autres, nous vivons en 1910, nous causons tous les jours avec les vivants des différents partis; et vous, vous paraissez vivre dans une année qui n'a pas de millésime, et vous allez et venez sur la planète comme un étranger, sans contact véritable avec vos contemporains. Et cependant, par vos aspirations tout au moins, vous êtes des nôtres; car, dans les reproches mêmes que vous nous faites (reproches non mérités), je retrouve les sentiments de nos coeurs". ${ }^{9}$

Nettlaus vor allem auf dem Gebiet der libertären Ideen und Bewegungen ausgewogen aufgebaute Bibliothek ist in ihrer Art die umfangreichste der Welt. Er erwarb das beinahe alle Sprachen umfassende und überwiegend aus dem neunzehnten und dem Anfang des zwanzigsten Jahrhunderts bis 1914 stammende Material grösstenteils in den Jahren 1887 bis zu dem

8 Mündliche Mitteilung von Arthur Lehning.

9 Guillaume an Nettlau, 30. Dezember 1910, Archiv Nettlau, IISG. 1908 schrieb Guillaume einem französischen Genossen: „En attendant que cette prophétie de Michelet [en 1855] - c'est-à-dire: ,quand l'Allemagne sera l'Allemagne, ce Russe y aura un autel' - se réalise, c'est un Allemand d'Autriche, le Dr Max Nettlau, qui a élevé à Bakounine le monument que lui devait la postérité." A. Lehning, ,Michel Bakounine et les historiens”, in: Bakounine. Combats et débats, Paris 1979, S. 37. 
Ersten Weltkrieg. Zahlreiche Freunde, wie Peter Kropotkin, Elisée Reclus, Errico Malatesta und Jean Grave, unterstützten ihn hierbei nach Kräften. Als Sammler, der sein Material über alles liebte, bat er im Sommer 1925 den damals in Paris wohnenden Lehning: „Retten Sie nur recht viel gute Sachen auf den Pariser Quais: so habe ich das kaufen dort immer aufgefasst."10

Im Juni 1920 schilderte Nettlau ausführlich einem Freund die Art und Weise seines Sammelns und die Geschichte sowie den Umfang seiner Kollektion.

Ich [habe] die Grenzen des Sammelgebietes ausserordentlich weit gezogen. Nicht sogleich, aber in sukzessiver Entwicklung. Ich sah, wie in die Bibliotheken vielfach nur die Hauptwerke über einen Gegenstand gelangen und wie jedes eingehendere Studium sofort auf unendliche Lücken stösst, wie die Broschüren-, Zeitschriften-, Flugschriften-Literatur meist verloren geht oder sich zerstreut und nur mühsam von vielen Seiten her in oft kümmerlichen Resten zusammengebracht werden kann, von deren handschriftlichem, brieflichem und anderem Material und der sich bald verlierenden mündlichen Tradition ganz abgesehen. - Deshalb suchte ich von Anfang an gerade dieses so seltene erhaltene Material zu sammeln und unterliess vielfach die Anschaffung von Hauptwerken, weil diese nicht verloren gehen und sich ohnedies in den grossen Bibliotheken befinden. ${ }^{11}$ Mein Ideal wären Dossiers über die zahllosen einzelnen Teile des grossen Gebietes der Entwicklungsgeschichte des menschlichen Fortschritts, die für die einzelnen Ideen, Bewegungen, persönlichen Schicksale etc. alles erreichbare enthalten, von den ersten Artikeln oder Broschüren, mit aller Polemik, Diskussionen, allen Zeitungen zu den definitiveren Werken, mit den Zeitschriften, Briefen, historischen, bibliografischen und anderen Notizen usw., bis zu den Zeitungsausschnitten, bildlichen Darstellungen und Karikaturen etc. und zum geringsten leaflet, zum Plakat und zur handbill. - Natürlich konnte ich selbst das nur auf wenigen Gebieten in gewissem Grade erreichen; ich dachte aber früher, dass, wenn mein ziemlich umfangreiches Material derart geordnet vorliegen würde, das immerhin manchen den Anstoss geben könnte, ihr Material - wenn es die aktuelle, vor Verfolgungen zu sichernde, Bedeutung verloren haben würde - einem solchen gemeinsamen internationalen Archiv anzuschliessen, das ich stets als möglichst bald von meiner zufälligen und vergänglichen Person getrennt betrachtete, wenn nur eine gesicherte Grundlage dafür zu finden wäre. Einstweilen fuhr ich fort, anzuhäufen und tue das heute noch mit den schwächsten Kräften. Dies erklärt Ihnen den räumlich kolossalen Umfang der Sammlung, da ich eben das Material nicht nur in seinem letzten Stadi-

10 Nettlau an Lehning, 17. August 1925, Archiv Lehning.

11 Die meisten Bibliothekare, meinte er, verachteten Broschüren, ,sie werden lieber fünfzig seltene Broschüren los um ein dickes Buch hinzustellen, das ruhig da steht und keine Mühe mehr macht." Nettlau an Annie Adama van Scheltema, 12. Juli 1939, IISG. 
um als Broschüren und Bücher von massgebendem Charakter, sondern in seiner Entstehung, Verbreitung und allen seinen Ausläufern zu konservieren suchte.

Ich habe oft an die vielen alten, totgeborenen ersten Lokomotiven, die nicht von Stephenson sind, gedacht, die im South Kensington-Museum zu sehen sind; dadurch, dass sich die Konstruktion Stephensons durchgesetzt hat, sind alle anderen unnütz geworden - und doch sammelt man sie. Dasselbe betrifft all die fehlgeschlagenen, ausgestorbenen Bewegungen neben den wenigen Richtungen, die sich wirklich durchgesetzt haben. Die Lösung scheint mir die zu sein, dass jede praktische Erziehung und Fortbildung in erster Linie bezweckende Sammlung die Hauptrichtungen und das modernste Material in erste Linie stellen wird - dass aber doch auf der grossen Erde für eine oder einige historische Sammlungen Platz sein sollte, wo die nicht reüssierenden Sozialisten wie die nicht Stephensonschen Lokomotiven ein Asyl finden würden. Ich hatte immer Sympathie für die schwächeren, nicht erfolgreichen Sachen, und so war mir nichts auf diesem Gebiet zu gering, ohne dass ich persönlich die Kleinigkeiten überschätzen würde. Ich strebte nie nach der Einheit, freute mich über jede Verschiedenheit, und das kam der Sammlung zugute, die, sagen wir, das sozialistische Flusssystem bis zu den geringsten Bächen hinauf nach Möglichkeit verfolgt und den sich im Sand verlierenden Steppenflüssen und den von Felsen verschlungenen, aber doch anderswo wieder auftauchenden Karst-Flüssen Interesse zuwendet, während, wenn die Bewegung einmal ein grosser Fluss geworden ist, sie mich weniger interessiert, weil sie dann doch nicht mehr verloren geht und meiner schwachen Kräfte nicht bedarf. [...]

Eine weitere Ausdehnung gewann die Sammlung dann dadurch, dass ich sie nicht mehr wie im ersten Anfang auf anarchische und möglichst sozialrevolutionäre Literatur beschränkte. Jahrelang verzichtete ich auf die ältere Literatur ganz und verlor dadurch unendlich viel, da in den Achtzigern und Neunzigern diese Literatur noch billig war. Ich holte das dann von etwa $1900 \mathrm{ab}$ in London und Paris intensiv nach - für deutsche Sachen war es schon zu spät. Immerhin tat ich, was ich nur konnte, für ältere Sachen und habe doch ziemlich viel. - Dann folgte ich der sozialdemokratischen Literatur, wenigstens in den Hauptländern und den kleineren Erscheinungen; auf die zahllosen Bücher musste ich verzichten, soweit ich sie nicht billig fand oder sie besonderes historisches oder theoretisches Interesse haben. - Den Syndikalismus konnte ich besonders durch ungeheure Zeitschriftenmassen, die mir seit vielen Jahren zur Verfügung gestellt wurden (Tauschblätter), ganz gut vertreten sehen, und so auch viele andere, sich spezialisierende Richtungen. - Erziehung, Antimilitarismus, Neomalthusianismus, moderne Literatur etc. - Dann hatte ich Gelegenheit, besonders in Paris, die französische radikale politische Literatur, von der Revolution bis 1870 , intensiv zu sammeln und ähnliches für England seit dem achtzehnten Jahrhundert, etc. Dann nahm ich alles soziale Reformen betreffende mit, alles sozial-deskriptive, Freidenker, Frauen, Frieden, Kooperationen, Nationalitäten, soziologisches aller Art, ebenso alle Spuren 
freiheitlicher Ideen, alles revolutionsgeschichtliche usw., immer mit der Vorliebe, entlegenes, verschollenes lieber zu ,retten" (rescue) als bekannte Sachen.

Dann kam der Krieg, der mich, als ich im April 1914 aus Paris nach Wien gekommen war, hier also traf, wo ich dann die ganzen Jahre zubrachte. Damit war die Sammlung abgeschnitten, obgleich für mich in Paris und, ich denke, auch in London vieles, speziell Zeitschriften, aufgehoben werden (in Paris unendliche Massen, so dass hier der Faden noch nicht abgerissen ist). ${ }^{12}[\ldots]$

Sie sehen also, dass meine kleine Sammlung ein etwas unbequemes grosses Möbelstück ist - nicht ein Steckenpferd mehr, sondern eine ganze Herde von wilden Steckenrössern, die bei der auf den dreissigsten Teil (jetzt) reduzierten ausländischen Kaufkraft des hiesigen Geldes mich geradezu zerstampfen und zertreten. - Der Umfang ist etwa folgender:

Anarchistisches, Bücher und Broschüren: 3.200; Zeitschriften: 1.200;

Freiheitliches (dabei auch der revolutionäre Teil des Syndikalismus etc.): 1.300 Druckwerke und 600 Zeitschriften;

Sozialistisches: 10.500 Druckwerke und 2.750 Zeitschriften;

Sozialreform: 2.000 Druckwerke und 2.300 Zeitschriften;

Politisch-Radikales etc.: 13.000 (inkl. die Zeitschriften).

Das gibt 36.850; - dazu mehrere tausend weniger prononzierte Literatur, wodurch 40.000 erreicht, wenn nicht überschritten wird. Dazu dann die tausenden kleineren Sachen. Dabei sind mehr als 10.000 verschiedene Zeitungen und Zeitschriften, von denen teils einzelne Nummern, teils sehr viele oder alle Nummern, manchmal ganze Kisten voll, vorhanden sind; diese bewirken eben die ungeheure räumliche Ausdehnung. ${ }^{13}$

Infolge der Inflation verkehrte Nettlau zu diesem Zeitpunkt bereits in schwierigen finanziellen Verhältnissen. Auffallend offen erläuterte er ein Jahr später Joseph Ishill ${ }^{14}$ seine Situation.

12 Kropotkin z.B. war es bis zu seiner Rückkehr nach Russland Juni 1917 zur Gewohnheit geworden, Material, das er nicht selbst aufbewahren wollte, in einer für Nettlau bestimmten Kiste aufzuheben.

13 Nettlau an Siegfried Nacht, einen nach Amerika emigrierten österreichischen Anarchisten, 13. Juni 1920, IISG, auch in Rocker, Max Nettlau, a.a.O., S. 226-30. Vgl. M. Vuilleumier, „Les sources de l'histoire sociale: Max Nettlau et ses collections", in: Cahiers Vilfredo Pareto, Revue européenne d'histoire des sciences sociales, Nr 3 (1964), S. 195-205. - Als ich 1970 als Bibliothekarin des IISG begann, den Zeitschriftenkatalog mit etwa 30000 Titeln der Vorkriegssammlung für die Publikation in Buchform vorzubereiten, schlug ich dem bei der Koninklijke Bibliotheek in Den Haag angeschlossenen Centrale Catalogus van Periodieken die Aufnahme des IISG-Bestandes vor. Zuerst war man begeistert, als man die Titelmenge hörte, begann man zu zögern, als sich aber herausstellte, dass sicher $80 \%$ des Bestandes inkomplett und in vielen Fällen nur Einzelnummern vorhanden waren, lehnte man ab. Für solch eine Sammlung, die qua Umfang dem damaligen Zentralkatalog gleichkam, bestand kein Interesse. Auf dem Gebiet des Sozialismus und der Arbeiterbewegung ist sie eine der seltensten Kollektionen der Welt. 14 Joseph Ishill, 1888 in Rumänien geboren, emigrierte 1909 nach den USA und fand 
Geboren 1865, fühlte ich mich bereits seit 1880 als Sozialist und Anarchist. Ich hatte niemals den Wunsch, mir eine Karriere zu verschaffen oder mich als Geschäftsmann zu betätigen, und die aussergewöhnliche Zärtlichkeit meiner Eltern erlaubte mir, ein Studium zu betreiben, von dem ich kaum einen Gewinn erwarten durfte. Ich studierte zunächst vergleichende indoeuropäische Sprachwissenschaft und ging von 1882-87 zu einem Spezialstudium der celtischen Sprachen über. Die alten irischen und kimberischen Manuskripte im Britischen Museum führten mich zuerst nach England, wo ich seit 1885 zuerst mit der Socialist League und William Morris und seit 1888 mit Kropotkin bekannt wurde. Nach dem unerwarteten Tod meines Vaters 1892 befand ich mich in einer bescheidenen unabhängigen Lage, die mir die freie Wahl liess, meine celtischen Studien weiter fortzusetzen oder historische Forschungen über Sozialismus und Anarchismus und vor allem über das Leben Bakunins zu betreiben. Ich entschied mich für das Letztere, denn die Manuskripte, Dokumente und die Menschen, die Bakunin gekannt hatten, waren in alle Welt zerstreut und verschwanden allmählich. So reiste ich jahrelang herum, von 1892-96, auf der Suche nach Material für Bakunins Leben und Wirken und schrieb eine umfangreiche Bakunin-Biografie (1896-1900). ${ }^{15}$ [...] Ich reiste die ganze Zeit und war jedes Jahr in Wien, Genf, Paris und London. Dazwischen sammelte ich in grossem Umfang die vorgeschrittenste soziale Literatur; doch davon will ich hier nicht reden; ich will nur bemerken, dass meine Sammlung mich heute grosse Opfer kostet und mir zu einer schweren Bürde geworden ist, so dass ich bloss noch ein Ziel habe, die Sachen bald auf einem bestimmten Platz zusammen zu haben, um alles richtig einteilen zu können. [...]

Auf diese glückliche Art vollzog sich mein früheres Leben. Ich lebte in den grossen Bibliotheken und zusammen mit Kameraden, war auf der Jagd nach seltenen Büchern und wanderte häufig durch die Wälder Österreichs und der Schweiz über Berge und Täler oder lebte in meinem Geburtsort mitten im Wiener Wald oder in Wien selbst, wo einst meine Eltern aus

dort als Setzer Arbeit. 1923 gründete er The Oriole Press und gab mehrere bibliophile Bücher über u.a. Kropotkin und die Brüder Elie und Elisée Reclus heraus. - Wie sehr Nettlau jede Publizität um seine Person scheute, zeigte sich 1924, als der argentinische Anarchist L. J. Guerrero in aller Unschuld in dem Blatt Argonauta dazu aufgerufen hatte. Nettlau aus seiner bedrängten finanziellen Lage zu helfen. Ausser sich, bat Nettlau Lehning. alles zu unternehmen, dass diese ,wohlmeinende aber unentschuldbare" Indiskretion nicht auch von der niederländischen anarchistischen Presse übernommen werden würde, und fügte hinzu: „Ich bin empört und niedergedrückt im höchsten Grade."

15 Da er für die 1281 handgeschriebenen Seiten in folio keinen Verleger fand, zog er selbst fünfzig Exemplare nach einem ingeniösen Verfahren ab unter Zuhilfenahme von Gelatine, Pergamentpapier, einer Spezialtinte und Gummirollen. Er schickte je ein Exemplar an die Nationalbibliotheken in London, Paris, Sankt-Petersburg und Brüssel, an die Königliche Bibliothek in Berlin und Dresden, an die Universitätsbibliotheken in Wien und Genf und an die Stadtbibliotheken in Bologna und Wien. Auch verschiedene Freunde, so Landauer und Kropotkin, erhielten ein Exemplar, und im Tausch bekam er von H. P. G. Quack dessen De Socialisten. 
Deutschland eingewandert waren. Bei alldem verdiente ich natürlich nie einen Heller mit meinen Arbeiten und war immer noch imstande, Dinge zu unterstützen, die mir am Herzen lagen. Das alles konnte ich tun mit einem jährlichen Einkommen von ungefähr siebentausend österreichischen Kronen, die damals einen Wert von siebentausend Franken oder vierzehnhundert amerikanischen Dollar hatten. ${ }^{16}$ Ungefähr die Hälfte meines Einkommens pflegte ich für Bücher und die Miete zu verwenden. ${ }^{17}$ Die andere Hälfte genügte mir für meine Reisen und um ein einfaches, aber bequemes Leben zu führen, wohin ich immer kam, denn ich fühlte mich überall zu Hause. Das waren glückliche Jahre, die nur durch den Tod meiner Angehörigen getrübt wurden, der meine persönliche Einsamkeit verursachte.

Seit April 1914 war ich in Wien und entging so den Heimsuchungen des Krieges im Ausland. Und hier bin ich heute noch. Da ich mich keiner Begünstigung zu erfreuen hatte, so ging es mir wie so vielen anderen armen Leuten, das heisst: immer mehr bergab. Bis zum Herbst 1918 ging es noch einigermassen, dann aber wurde mir das Leben in immer schnellerem Tempo zur Hölle, und so ist es noch heute. Ich benutzte mein kleines Vermögen nie für geschäftliche Zwecke oder zu Spekulationen, sondern verbrauchte einfach die üblichen Zinsen; noch tat ich während und nach dem Kriege irgend etwas, um mich zu sichern. Durch die ungarische Sowjet-Revolution schrumpfte das kleine Einkommen auf viertausend Kronen zusammen. Das waren vor dem Krieg achthundert Dollar pro Jahr, heute aber, wo der Dollar siebenhundert Kronen gilt, ist das weniger wie sechs Dollar pro Jahr. So bin ich also ein kapitalistischer Nichtstuer mit einem Jahreseinkommen von sechs Dollar.

[...] $\mathrm{Zu}$ bekommen ist hier alles, doch die Preise sind für mich unerschwinglich. Trotzdem schlage ich mich durch, indem ich die kleinen Summen, die mir zur Verfügung stehen, fast ausschliesslich auf Nahrung verwende, wobei ich mehr auf die Qualität als auf die Quantität achte, die ich zu einem relativ billigen Preis gerade auftreiben kann. Ich lebe häufig von zwei Pfund amerikanischen, in Büchsen konservierten Bohnen mit Speck, hauptsächlich Bohnen und fast kein Speck, für die ich zwanzig bis zweiundzwanzig Kronen zahle, weniger als drei Cents. Diese Büchsen wurden wahrscheinlich früher hier eingeführt, als der Dollar noch niedriger im Kurs stand und 150 Kronen ausmachte, anstatt 720 , wie vor einem Jahr. $\mathrm{Zu}$ diesen Bohnen kommt noch etwas Brot und von Zeit zu Zeit ein paar Kartoffeln und gelegentlich etwas Reis oder Mehl in Wasser gekocht. Alles andere ist ausgeschlossen; vielleicht, dass während des Winters noch ein paar Äpfel dazukommen. Auf diese Weise lebe ich mit einem Einkommen, das ungefähr ein Drittel oder ein Viertel von dem eines jungen ungelernten

165600 Mark nach dem damaligen Wechselkurs. Das Jahreseinkommen eines Zeitschriftenredakteurs betrug etwa 1800 Mark.

17 Nettlau hat in dreissig Jahren bis ca 1921 insgesamt etwa 50000 Goldfranken in seine Sammlung investiert. 
Tagelöhners ausmacht oder ein Zehntel von dem, was heute ein gelernter Arbeiter verdient; doch blieb ich bisher gesund dabei. ${ }^{18}$

[. . .] Dabei steigen die Kosten für den Lebensunterhalt beständig. Diesen Morgen las ich, dass die Postspesen von heute an verdoppelt werden; der Preis des Brotes ist bereits um die Hälfte gestiegen und steigt noch jeden Tag. Mit den höheren Preisen gehen natürlich die Löhne der Arbeiter und die Gehälter der Beamten in die Höhe, und so geht es fort ohne Ende. Um den Ansprüchen zu genügen, druckt man Tag und Nacht neues Geld. So geht das seit Jahren Monat für Monat in einem immer rascheren Tempo. so dass Menschen wie ich; die sozusagen ausserhalb des allgemeinen Zirkels leben, mit der gröbsten Nahrung vorlieb nehmen müssen, die für mich noch immer eine Erquickung ist, denn es gibt noch eine Stufe, die ich bis jetzt nicht erreicht habe - nämlich von Runkelrüben und ähnlichem leben, was vielen Menschen hier bereits den Tod gebracht hat.

Sozialisten und Kommunisten, die im Besitz von Ämtern sind, finden sich nicht schlecht dabei; es ist dies eine Klasse, von der ich noch weiter entfernt bin als von den Bourgeois und Arbeitern, die unter gewöhnlichen oder mittleren Bedingungen leben. Auch die Kapitalisten und Spekulanten gedeihen ganz prächtig dabei. Den Bauern geht es auch nicht schlecht, und das Heer der Beamten wird mit jedem Tag zahlreicher und mächtiger. Nur Sechs-Dollar-Kapitalisten wie ich oder ungelernte, nur intellektuelle Arbeiter, zu denen ich mich ebenfalls rechne, da ich mein ganzes Leben lang nie ohne Bücher war, nur sie gehen vor die Hunde. ${ }^{19}$

Nettlau hatte seine Sammlung in Wien, München, London und Paris in Depots untergestellt. Die schon durch den Umfang bedingten Lagerkosten machten nun eine Frage dringend, die sich der Besitzer bereits früher gestellt hatte: wo konnte die Kollektion ihre sichere Bestimmung finden? Anfangs beabsichtigte Nettlau, seine Bibliothek dem British Museum zu hinterlassen, seine Entrüstung über den Burenkrieg liess ihn jedoch davon Abstand nehmen. 1907 bot sich eine andere Möglichkeit an. Nettlau erwog eine Schenkung zugunsten der Universitätsbibliothek in Genf, erste Besprechungen hatten bereits mit der Direktion stattgefunden. Ein Jahr später hinterliess ein anderer grosser Sammler, das ehemalige Mitglied der Pariser Commune Jules Perrier, auf Empfehlung seiner Freunde Elisée Reclus und Nettlau eben dieser Genfer Bibliothek seine Kollektion. Als Nettlau Mitte September 1908 in Genf eintraf, hörte er, dass die Bibliothek Dubletten aus dieser Sammlung verkauft. Er eilte hin und entdeckte zu seiner grossen Entrüstung auch einige Kubikmeter ungebundener Zeitschriften, viele Rollen Affiches und Hunderte Broschüren - alles Material aus der Zeit von 1830 bis nach der Commune. Wie sich herausstellte,

\footnotetext{
${ }^{18}$ Nettlau suchte selbst in jenen Jahren in der Umgebung von Wien gerodete Felder nach Kartoffeln ab.

${ }^{19}$ Rocker, Max Nettlau, S. 212-15.
} 
hatte der Direktor einem Angestellten aufgetragen, alles aufzulösen, wenn möglich gegen Bezahlung, man hätte keine Verwendung dafür. Das Chaos übersehend, verzichtete Nettlau auf seinen ursprünglichen Plan und versuchte nur noch "für meine Sammlung davon zu retten, was ich retten konnte" (darunter auch das äusserst seltene, erste kommunistisch-anarchistische Blatt l'Humanitaire, organe de la science sociale, von dem nur zwei Nummern 1841 in Paris erschienen waren). Einige Jahre später setzte er die Königliche Bibliothek in Berlin als Erben seiner Kollektion ein, blieb aber weiterhin beunruhigt über deren endgültiges Schicksal: ein Thema, das er wiederholt bei Besuchen von Lehning in Wien aufnahm.

Anfang 1924, so Nettlau in seinen Memoiren,

kam einmal ein junger Deutscher, der ganz in Holland aufgewachsen war, aber von dort seit ein oder zwei Jahren nach Berlin gekommen war, wo ich ihn im Syndikalist und anderen Blättern häufig erwähnt gesehen hatte: Arthur M[üller]-L[ehning]. ${ }^{20} \mathrm{Er}$ reiste mit seiner Frau und wollte mehrere Monate in Wien zubringen. Er war nach meinem Eindruck einer der jungen Holländer und Skandinavier, welche den Anarchismus theoretisch anerkannten, seinen religiösen Deformationen fern standen, aber ganz in Syndikalismus und Antimilitarismus und Organisationsbestrebungen aufgingen, was ich für eine ganz unzweckmässige Kraftverwendung hielt, solange so unendlich wenige wirkliche Ideenpropaganda betrieben [...]. Die Freude an der Anarchie fehlte ihnen; sie glaubten, es genüge, wenn das alles in Syndikalismus, Antimilitarismus und andern Spezialisationen einen organisierten Ausdruck finde [...]. ${ }^{21}$

Dieser junge Mann [kam] auf den Gedanken, dass meine Sammlung am besten in Holland ihren Platz finden würde, weil dafür einige günstige Faktoren vorhanden seien, was er beurteilen und nach Möglichkeit fördern konnte und wollte, was mir aber unbekannt war. Ich gab ihm freie Hand unter Bedingung der absoluten Diskretion [. . . ]. Ich musste jeder Möglichkeit, diese Frage endlich für mich zu lösen, entgegenkommen, und hatte für eine holländische Lösung nur von Anfang an die volle Sympathie. Holland ist ein Land alter gelehrter Arbeit und der sorgfältigen Pflege der Vergangenheit. Es lag mitten zwischen den grossen Gegenden englischer, französischer und deutscher Forschung und war der richtige Platz für neutrale internationale Einrichtungen wie sonst damals nur noch die Schweiz. Genug, ich freute mich über diese neue ferne Möglichkeit, ohne dass etwas

20 Der Syndikalist, Berlin 1919-33, war das Organ der Dezember 1919 gegründeten syndikalistischen Gewerkschaftsorganisation "Freie Arbeiter-Union Deutschlands". Lehnings erster Artikel, „Der holländische Antimilitarismus”, erschien 1922 als Beilage zu Nr 49. Die ,andern Blätter” sind wahrscheinlich Revolt, das Organ des norwegischen sozialanarchistischen Bundes und die österreichische Zeitschrift Erkenntnis und Befreiung, Organ des herrschaftslosen Sozialismus.

21 Als Lehning Nettlau 1935 mitteilte, dass er nun auf dem IISG arbeite, antwortete dieser, dass er sich freue, dass er statt Syndikalisten nun Bücher organisieren würde! 
weiteres damals geschehen oder besprochen werden konnte als, dass er stille Bemühungen machen werde. Bei meiner grossen Getrenntheit von Holland, so sehr ich einige gute holländische Bekannte gehabt hatte, ${ }^{22}$ und dem Fehlen neuer Anknüpfungen in den Jahren seit Ende des Kriegs, ist klar, dass die Originalität dieser Idee, die schliesslich am Ende von 1935 zur Ausführung gelangte, also mein späteres und jetziges Schicksal bestimmte, A.M.L. angehört, da ich wirklich bevor er zu mir kam, nicht den leisesten Gedanken daran hatte, dass sich Faktoren in Holland für meine Sammlung interessieren könnten. Das sind Tatsachen. ${ }^{23}$

Die von Nettlau erwähnte Möglichkeit lag in der Vereinigung seiner Kollektion mit der 11000 Bände zählenden Bibliothek Domela Nieuwenhuis', die dem Ferdinand Domela Nieuwenhuis Fonds am 21. März 1922 von der Witwe geschenkt worden war. ${ }^{24}$ Damals, 1924, konnten hierfür keine Mittel freigemacht werden. 1934 übergab der Fonds die Bibliothek und das Archiv Domela Nieuwenhuis' als Leihgabe der EconomischHistorische Bibliotheek, deren Direktor der Professor für Wirtschaftsgeschichte an der Universität Amsterdam Dr N. W. Posthumus war. ${ }^{25}$

„Von dem Juristen und Wirtschaftshistoriker Posthumus wurde dasselbe wie von Oldenbarnevelt gesagt: ,Een man van grooten bedrijve, besoigne, memorie en directie, ja singulier in alles.' Sein Ruhm als Organisator der Wissenschaften wird unzweifelhaft weiterleben." ${ }^{26}$ Auch in der

22 U.a. Ferdinand Domela Nieuwenhuis (1846-1919).

${ }^{23}$ Nettlau, Erinnerungen und Eindrücke, Zweite Serie, Heft 1, S. 25-28, IISG. Er schrieb sie in achtundzwanzig engbeschriebene Schreibblöcke während des Zweiten Weltkriegs.

24 Der Fonds war 1914 von überwiegend aus der revolutionären Gewerkschaftsbewegung stammenden Gesinnungsgenossen Domela Nieuwenhuis' mit dem Ziel gegründet worden, ihn seiner finanziellen Sorgen zu entheben. Nach seinem Tod unterstützte er noch jahrelang Sohn und Witwe. nach dem Ableben letzterer am 3. April 1933 wurden die Gelder des Fonds zugunsten der Bibliothek verwendet.

25 „Die Bibliothek von Domela Nieuwenhuis passt ausgezeichnet in den Rahmen der Economisch-Historische Bibliotheek", so Posthumus auf der Eröffnung am 25. Februar 1934. Und er fuhr fort, dass es in der Ökonomie nicht nur um Geschäftstransaktionen und Waren ginge, sondern an erster Stelle um den Menschen, den Arbeiter, deshalb sei auch eine besondere Abteilung für Material mit Beziehung auf die Arbeiterbewegung eingerichtet worden. De Syndikalist (Amsterdam), 3. März 1934. Nettlau war übrigens der Meinung, ,dass F.D.N. kein eigentlicher Sammler war, wozu ihm Zeit, Geld, Konzentriertheit, Liebhaberei fehlten, sondern dass er wie ein Gelehrter, Publizist, Politiker, Geistlicher, allbekannter Mann in 60 Jahren eine Masse Sachen sich anhäufen liess oder sich für Arbeiten besorgte, so dass die Bestände äusserst ungleichartig und unproportioniert sind." Erinnerungen und Eindrücke, Zweite Serie, Heft 4, S. 162. Im Brief vom 12. Juli 1939 schreibt er an Annie Scheltema: „Bibliotheken sind eben wie Menschen: wenige sind von Interesse, aber jeder will doch dasein!", IISG.

${ }^{26}$ So Lehning in seiner Rede bei der Verleihung der Ehrendoktorwürde durch die Universität von Amsterdam (Arthur Lehning. Amsterdam, 8 januari 1976, Amsterdam 1976, S. 20). Er fuhr fort: „Ich habe ihn vor gut einem halben Jahrhundert, um genau zu 
Geschichte von Nettlaus Sammlung soll Posthumus eine sehr grosse Rolle spielen, darum hier etwas mehr über diesen gelehrten Geschäftsmann und Organisator. 1880 in Amsterdam geboren, studierte er dort auch die Rechte. Seine Dissertation 1908 wird der erste Band sein von De geschiedenis van de Leidsche lakenindustrie, ${ }^{27}$ dem „Modell einer Industriegeschichte". 1913 folgte er dem Ruf als Professor für Wirtschaftsgeschichte auf den ersten Lehrstuhl dieses Faches an die Handelshochschule zu Rotterdam, der heutigen Erasmus-Universität, 1922 an die Fakultät der Handelswissenschaften der Universität von Amsterdam. 1914 gründete er in Den Haag das Nederlandsch Economisch-Historisch Archief, 1932 folgte die Economisch-Historische Bibliotheek, die nach vergeblichen Bemühungen um Unterstützung seitens der Stadt Den Haag ihren Sitz in Amsterdam bekam. ${ }^{28} 1935$ verwirklichte Posthumus das wichtigste der von ihm gegründeten Institute, das Internationale Institut für Sozialgeschichte, dem er, mit Unterbrechung während der Kriegsjahre, bis 1952 als Direktor vorstand. Noch während des Zweiten Weltkrieges wurde auf seine Initiative die Gründung des Rijksinstituut voor Oorlogsdocumentatie vorbereitet, dessen Direktorium er als Mitglied und Vorsitzender ${ }^{29}$ bis zu seinem durch einen Konflikt mit L. de Jong Juni 1949 verursachten Rücktritt angehörte. In derselben Zeit plante er mit Jan Romein die Gründung einer Fakultät der Sozialwissenschaften an der Universität von Amsterdam.

1949 emeritiert, nahm er im Alter von neunundsechzig Jahren noch die Leitung des wissenschaftlichen Verlages E. J. Brill in Leiden auf sich, dem

sein vor 56 Jahren, in Rotterdam kennengelernt, als ich bei ihm Wirtschaftsgeschichte hörte. Nach meinem Fortgang aus Rotterdam habe ich den Kontakt mit ihm nie abbrechen lassen. Er war es, der mir 1935 die Mitarbeit bei der Gründung des Internationalen Instituts für Sozialgeschichte anbot und der im Ruhestand, als Direktor des Verlags Brill in Leiden, die Initiative zur Herausgabe der Archives Bakounine nahm. Es hătte mich sehr gefreut - und ich bin überzeugt, ihn auch - wenn Posthumus dieser Feier hätte beiwohnen können.” Professor I. J. Brugmans schrieb über Posthumus: „Durch seinen Unterricht, mehr noch durch seine wissenschaftlichen Schriften, am meisten aber durch die Institute, die er gründete, wird er noch lange Jahre fortleben.” "In memoriam prof. mr. dr. N. W. Posthumus", in: Nieuwe Rotterdamse Courant, 20. April 1960.

27 Vgl. Bibliografie van de geschriften van Nicolaas Wilhelmus Posthumus (1880-1960), Rotterdam 1981.

28 Bereits im Mai 1930 hatte die Stadtverwaltung von Amsterdam dem Ankauf der zwei Grundstücke auf der Herengracht sowie einer jährlichen Subvention von fl 4000 zugestimmt. Jahresbericht des Vorstands, Economisch-Historisch Jaarboek, Bd 17 (1931), S. XXXVI.

29 Boris Nikolaevskij, dem früheren Mitarbeiter auf dem IISG. schrieb er hierüber im November 1945: „At present I am very busy in the same function that you held at the time. The Government has appointed me president of the Board of the National Institute for the Documentation of the War. You were the dictator of a similar Institute in Russia at the time. In Holland, being a democracy, a triumvirate has been appointed." Kopie, Archiv Lehning. 


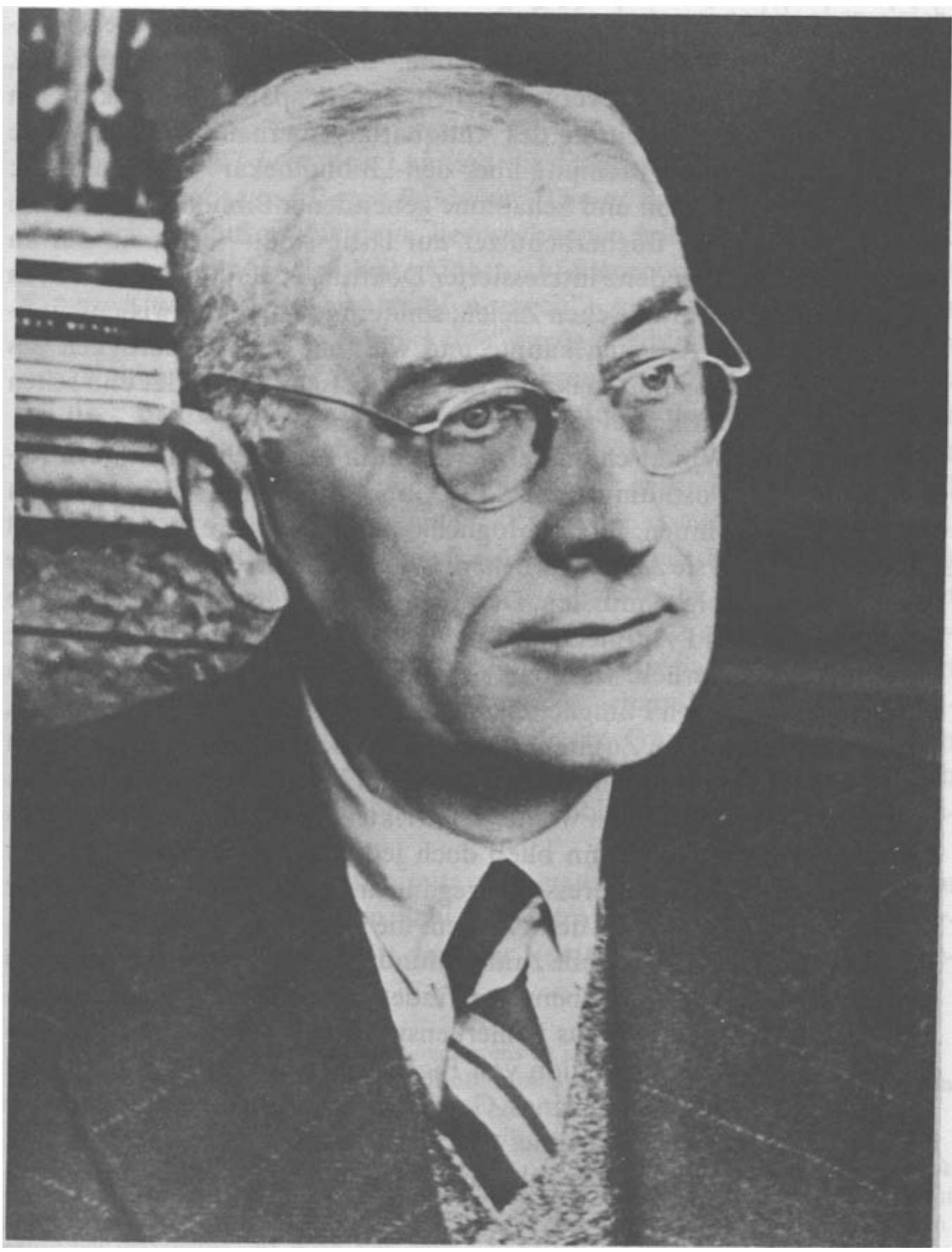

Professor Dr N. W. Posthumus 
er bereits früher als Mitglied des Aufsichtsrats zur Verfügung gestanden hatte. P. J. van Winter wird später anlässlich dieses Schrittes sagen: „Die Liebe zum Buch, auch zum Kuriosum, sollte ihn sein ganzes Leben begleiten. Die Bibliotheken und Institute, die er mithalf aufzubauen, bezeugen es. Es war nicht verwunderlich, dass er später als Direktor von E. J. Brill freudig die Leitung des Antiquariats übernahm."30 Die Worte schliessen an Nettlaus Meinung über den „Bibliothekar” Posthumus an: ,weder ein an Tradition und Schablone gebundener Bibliothekar, dem im Grunde Bücher und Bücherbenutzer nur lästig sind - noch ein nur an einer bestimmten Tendenz interessierter Doktrinär oder Fanatiker - noch ein Lehrer mit nur praktischen Zielen, sondern jemand, der wissenschaftliches historisches Arbeiten kannte und wie sehr dazu Vielartigkeit des direkten Materials gehört, das man so selten beisammen findet und selten so vielartig wie zufällig bei mir’. ${ }^{31}$

Professor van Winter charakterisierte ihn in seinem Nachruf auch folgendermassen: „Posthumus besass die Gabe, andere für seine Ansichten und Pläne zu gewinnen. Er sah Möglichkeiten, die andere übersahen und fand den Weg, um sie zu verwirklichen. Oft nahm er die Zustimmung derer vorweg, die ihm folgen mussten. Den Unwillen der Uberrumpelten wusste er mit Charme und Aufmerksamkeit zu überwinden, blieb eine gewisse Empfindlichkeit zurück, war man sich doch darüber einig, dass hier ein Mann mit besonderen Fähigkeiten am Werk war. Alles was er unternahm, stand in einem grossem Zusammenhang. Kleiṇlichkeit und Beschränktheit waren ihm fremd, und wenn er sich manchmal in seinen Projekten und den Interessen, denen er dienen wollte, verstrickte und das nötige Unterscheidungsvermögen verlor, dann blieb doch jeder davon überzeugt, dass er vom grossen Allgemeininteresse ausgegangen war und auch dahin wieder zurückkehren würde."32 In den Notizen, die sein Nachfolger Professor A. J. C. Rüter für die Gedenkrede zum fünfundzwanzigjährigen Bestehen des Instituts im Dezember 1960 benutzte, findet man auch über den im selben Jahr verstorbenen Posthumus bemerkenswerte Worte: „Aussergewöhnlicher Mann durch Kombination von Eigenschaften: Beschaulichkeit und Tatendrang, Eigenschaften eines Gelehrten und Organisators; schnelle Intelligenz, aggressive Energie, Sachverständnis, Menschenkenntnis. Nicht zu vergessen, um das Bild zu vervollständigen: seine unfassbare

30 P. J. van Winter, „Herdenking van Nicolaas Wilhelmus Posthumus (26 februari 1880 - 18 april 1960)", in: Jaarboek der Koninklijke Nederlandse Akademie van Wetenschappen, 1960-1961, S. 346. Professor v. Winter gehörte dem Vorstand des IISG von 1935 bis 1948 an.

${ }^{31}$ Nettlau, Erinnerungen und Eindrücke, a.a.O., S. 186.

32 Van Winter, „Herdenking van Nicolaas Wilhelmus Posthumus”, a.a.O., S. 352. 
Persönlichkeit und sein Charme."33 Seine früheren Mitarbeiter vom Institut sprechen von ihm meist mit grosser Bewunderung und erwähnen besonders seine ,intuitive Intelligenz". Er forderte sehr viel, aber gleichzeitig ging von ihm auch ein inspirierender und stimulierender Einfluss aus.

Im Sommer 1927 besprach Lehning die Frage der Sammlung mit dem gemeinsamen Freund Roger Baldwin. ${ }^{34}$ Dieser hatte bereits 1924, wahrscheinlich im Auftrag Nettlaus, Besprechungen mit der New York Public Library über die Möglichkeit geführt, ,to incorporate your collection at this most useful world center of research". Aber der Bibliothekar war davon überzeugt, dass wohl keine einzige Bibliothek auf Basis der von Nettlau geforderten jährlichen Leibrente die Kollektion erwerben würde. ${ }^{35}$ Baldwin schlug nun vor, die Sammlung einer grossen Bibliothek zu übergeben, und da die Bibliothek von H. P. G. Quack bereits einen Platz

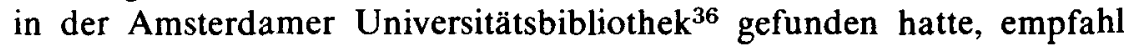
Lehning diese. Nettlau wollte die Sache aber lieber vorläufig ruhen lassen. Als Lehning Nettlau jedoch, nach Rücksprache mit Posthumus, Anfang 1928 schrieb, die Möglichkeit, seine Kollektion in den Niederlanden unterzubringen, nähme festere Formen an, da letzterer für das Nederlandsch Economisch-Historisch Archief sehr an der Sammlung interessiert sei, antwortete Nettlau postwendend ausführlich und enthusiastisch. Lehning konnte ihm nun bereits die mit dieser Transaktion verbundenen Bedingungen schreiben und fügte hinzu, bei einer Realisierung ,werde ich versuchen die F. Domela Nieuwenhuis Bibliothek auch dort anzugliedern".37

Am 17. März nahm Posthumus zum ersten Mal Kontakt mit Nettlau auf: „Von meinem früheren Schüler, Herrn Müller Lehning in Amsterdam, haben Sie schon gehört dass der Vorstand des ,Nederlandsch Eco-

\footnotetext{
33 A. J. C. Rüter, Historische studies over mens en samenleving, Assen 1967, S. 283.

${ }^{34}$ Roger N. Baldwin (1884-1981) war fünfundzwanzig Jahre lang Direktor der von ihm 1920 gegründeten American Civil Liberty Union.

35 Baldwin an Nettlau, 14. Januar 1925, Archiv Nettlau.

36 Vgl. Catalogus van de schenking-Quack, Amsterdam 1915. H. P. G. Quack (1834-1917) war u.a. Professor der Staatswissenschaften an den Universitäten zu Utrecht und Amsterdam und Direktor der Nederlandsche Bank. Sein Hauptwerk, De Socialisten. Personen en stelsels, ist noch stets eine der besten Ubersichten der Geschichte der sozialistischen Ideen. Vgl. den Reprint (Baarn 1977) mit einer Einleitung von A. Lehning und einer ergänzenden Bibliographie von M. Hunink und A. Lehning, sowie die ausführliche Besprechung von Carl Grünberg in dessen Archiv für die Geschichte des Sozialismus und der Arbeiterbewegung, Jg. 4, S. 150-54.

37 Lehning an Nettlau, 26. Februar 1928, Kopie Archiv Lehning.
} 
nomisch-Historisch Archief prinzipiell bereit ist mit Ihnen über die Erwerbung Ihrer Bibliothek zu überlegen. Persönlich würde es mich sehr freuen wenn es möglich sein würde eine so wichtige Bibliothek wie die Ihrige zusammen zu halten." Er wolle gern das eine und andere mündlich besprechen, ob Nettlau mit seinem Besuch am 3. April in Wien einverstanden wäre. ${ }^{38}$ Nettlau reagierte umgehend und positiv. Posthumus schickte ihm Informationsmaterial über das Archief, u.a. die hierfür von ihm selbst ins Deutsche übertragenen Statuten und eine Liste der Personen, die es finanziell unterstützten. Nettlau entdeckte den Namen Deterding, ,,der berüchtigste holländische ,Milliardär' [...] mit seinem mesopotamischem oder persischem und sonst allerortigem Petroleum. Ich lachte nicht schlecht, als ich diesen Namen sah, aber sowie Börne beim Hambacher Fest, 27. Mai 1832, als ihm seine Uhr gestohlen wurde, sagte, die Sache macht Fortschritte, da sich die Diebe dazu drängen, so dachte ich, das muss eine solide, dauernde, die Konservierung der alten Sachen sichernde Gründung sein, wenn ein Deterding Geld hineinsteckt."39

Einige Tage später berichtete Nettlau Lehning begeistert von den ,angenehmen Besuchen des Herrn Professors die ich Ihnen verdanke", auch freute es ihn sehr, dass das Archief nur ,diskret zugänglich" sei, ,d.h. nur für wirklich interessierte" ${ }^{40}$ In seinen Erinnerungen schreibt er hierüber:

Es gab für meine Sache eine, sagen wir, gelehrte und eine populäre Lösung. Mein Wunsch war seit der ersten Stunde die gelehrte Lösung - die Bücher usw. als Forschungsmittel und ihre grösste Konservierung und Schonung für kommende Zeiten. Die populäre Lösung bedeutet, dass solche Bücher usw. möglichst viel von unmittelbaren Interessenten, Studierenden, Arbeitern, Gesinnungsgenossen benutzt werden, was sie abnutzt, und dies kommt grade für diese Literatur der Armen in Frage, die aus billigstem und vergänglichstem Papier usw. hergestellt ist. Eine intelligente Bibliothek, wenn es eine solche gäbe, würde schon jetzt Drucke und Zeitungen der schlechtesten Holzpapierzeit wie Inkunabeln oder Kostbarkeiten behandeln, das heisst ihre ganz sorgfältige Behandlung durch ihre eigenen Angestellten und durch die Leser kontrollieren, wie man das für Seltenheiten tut. Ein an Kultur interessiertes Volk würde längst dafür gesorgt haben, dass von jeder Schrift und Zeitung 20 oder 50 Exemplare auf gutem Papier hergestellt werden und dass diese in die Bibliotheken gelangen, ebenso wie ordentliche Bibliotheken Fonds erhalten müssten, um zahllose zerlesene, abgenutzte Exemplare beständig durch neue zu ersetzen, aus dem Antiquariatshandel, und um von meistbenutzten Büchern rechtzeitig Reserveexemplare für die Zukunft anzuschaffen. Es gibt eine „Bücherhygienik” die mir grade so hoch

38 Posthumus an Nettlau, 17. März, Archiv Nettlau.

${ }^{39}$ Nettlau, Erinnerungen und Eindrücke, a.a.O., S. 163.

40 Nettlau an Lehning, 11. April, Archiv Lehning. 
steht, wie die menschliche Hygienik. ${ }^{41}$ Ich habe mehr Erfahrung in solchen Dingen als ,hohe Gelehrte”, denen meist Rezensionsexemplare oder neugekaufte höhere Bücher durch die Hände gehen, da ich als Büchersucher, oft schon mehr „Bücherbandstierer” Millionen von Büchern in allen Stadien der vielen Benutzung in den Händen gehabt habe. Darum sage ich, dass eine Konservierungsbibliothek und eine Volksbibliothek, Leihbibliothek, Vereinsbibliothek usw. radikal verschiedene Dinge sind. ${ }^{42}$

Posthumus hatte den Plan gefasst, ein Max Nettlau Institut zu gründen. Juni 1928 konnte Lehning Nettlau mitteilen, die Stadtverwaltung von Amsterdam habe ein Gebäude für die Bibliothek zur Verfügung gestellt, ein ehemaliges Pfandhaus auf dem Kloveniersburgwal. Posthumus würde ihm bei seinem nächsten Besuch Fotos mitbringen. Etwa zur gleichen Zeit schickte Posthumus Nettlau den Vorschlag des geschäftsführenden Vorstands betr. des eventuellen Ankaufs seiner Sammlung, den die Vorstandsmitglieder des Archiefs auf der nächsten Sitzung behandeln würden. Er umfasste u.a. folgende Punkte:

1. Jährlich erhält Nettlau fl 1700 , ein Teil hiervon wird für eine Leibrente zurückbehalten;

2. Es verbleibt eine Handbibliothek zu Nettlaus Verfügung. Teile der Sammlung sollen nicht allgemein zugänglich gemacht werden. Dubletten bleiben sein Eigentum. Bücher und Broschüren werden auf Wunsch von Nettlau in ihrem ursprünglichen Umschlag gebunden;

3. Das Archief gelangt in den Besitz der Sammlung, bestehend aus Büchern, Broschüren, Zeitungen, Zeitschriften, Dokumenten, Manuskripten, Affiches, Porträts, Abbildungen usw.;

4. Nettlau wird versuchen, die ihm in Bewahrung gegebenen Kollektionen für das Archief zu erwerben (das betrifft u.a. die Bakuninmanuskripte);

5. Er wird seine früher gemachten Testamente widerrufen;

6. Transport- und Verpackungskosten gehen zu Lasten des Archiefs; usw. ${ }^{43}$

Der Jahresbericht 1928 des Archief-Vorstands meldet zu diesen Entwicklungen folgendes:

41 Im Juni 1979 holte ein Bericht über die Bibliothèque Nationale in Paris die Tagespresse: 700000 Bücher mussten wegen ihres besorgniserweckenden Zustandes aus der Benutzung genommen werden. Die Ursache sei im Qualitätsrückgang des Papiers zu suchen, das seit 1870 im Umlauf ist; bei der Papierherstellung wurde damals der Lumpenanteil durch das säurehaltigere Holz ersetzt. Würden keine effektiven Massregeln getroffen, läge in fünf Jahren die Zahl der nicht benutzbaren Bücher bei fünf Millionen. NRC Handelsblad, 27. Juni 1979.

42 Nettlau, Erinnerungen und Eindrücke, a.a.O., S. 199.

43 Posthumus an Nettlau, 5. Juni, Archiv Nettlau. 
Anfang 1928 wurde die Aufmerksamkeit des Vorstands auf die Möglichkeit gelenkt, eine auf wirtschafts- und sozialhistorischem Gebiet sehr umfangreiche Bibliothek durch Kauf zu erwerben. Diese Sammlung befand sich im Ausland und umfasste ausser vielen Tausenden Druckwerken, auch Handschriften. Die gesamte Kollektion ist das Resultat jahrelangen Sammelns eines Gelehrten auf dem internationalen Markt. Nach ausführlichen Unterhandlungen mit dem Besitzer wurde eine vorläufige Regelung getroffen, die später durch einen definitiven Vertrag ersetzt wurde. Beim Schreiben dieses Berichts sind die Besprechungen über die Vertragsausführung noch nicht abgeschlossen, da der Besitzer im Interesse seiner Sammlung in einigen Punkten noch eine andere Regelung wünschte. Der Vorstand hat versucht, ihm so viel als möglich entgegenzukommen.

Der Erwerb einer so umfangreichen Sammlung legte dem Vorstand in zweierlei Hinsicht Verpflichtungen auf. Erstens musste der für den Kauf benötigte Betrag aufgebracht, zweitens für ausreichende Unterbringung gesorgt werden. Da es ausgeschlossen war, dass die Vereinigung die benötigte Summe aus eigenen Mitteln aufbringen konnte, wurde sich in diesem Fall um Unterstützung Interessierter bemüht. Der Vorstand ist erfreut, mitteilen zu können, dass dies noch 1928 gelang, so dass der Ankauf der Kollektion gesichert ist. Denen, die hieran mitarbeiteten, sagt der Vorstand an diesem Ort nochmals herzlichen Dank.

Was das Gebäude betraf, meinte der Vorstand, wäre es selbstverständlich gewesen, sich an die Stadtverwaltung von Den Haag um Mitarbeit zu wenden. In dieser Stadt hat das Archiv der Vereinigung seinen Sitz, das Gebäude verfügt aber nicht mehr über ausreichenden Raum, um die umfangreiche neue Buchkollektion aufnehmen zu können. Die Stadtverwaltung von Den Haag hat unserer Bitte jedoch nicht entsprochen, worauf wir uns an die Stadtverwaltung von Amsterdam wandten. Mit Schreiben vom 5. August 1928 erhielt unser Vorstand die Zusage, dass letztere sowohl ausreichende Räumlichkeiten für die Gründung einer ökonomisch-historischen Bibliothek (die auch dem Publikum zugänglich sein sollte), als auch einen Beitrag für die laufenden Kosten zur Verfügung stelle, alles unter Vorbehalt der späteren Genehmigung durch den Gemeinderat. Während der hierauf geführten Besprechungen mit Vertretern der Stadtverwaltung wurden für die neue Bibliothek sehr geeignete Räume in einem günstig gelegenen Gebäude angeboten. Das Ganze würde aus zwei sehr grossen Bibliotheksräumen, die zugleich als Lesesaal dienen, einem grossen Magazinraum (ausreichend für 100000 Bände), sowie diversen Lagerräumen, Sortierflächen usw. bestehen. Die Einrichtung würde die Stadt in engem Kontakt mit dem Vorstand ausführen. Im zweiten Halbjahr 1928 wurden hierüber verschiedene Konferenzen abgehalten. Die gemachten Zusagen entsprechen ganz unseren Bedürfnissen und Wünschen. Der Vorstand geht davon aus, dass die Planung demnächst dem Gemeinderat zur Genehmigung vorgelegt werden kann. ${ }^{44}$ 
Alles schien günstig zu verlaufen. Nettlau sorgte sich, wie er sagte, nur um eine Sache: die Kisten, die er lange vor dem Ersten Weltkrieg in London in einem Lagerhaus untergestellt hatte, und die, wenn man davon erführe, sicher als feindlicher Besitz beschlagnahmt werden würden. Lehning versuchte ihn zu beruhigen: Posthumus besässe gute Beziehungen zu Ramsay MacDonald über niederländische Sozialdemokraten, zu einflussreichen Londoner Kaufleuten über Kröller, ${ }^{45}$ zu dem niederländischen Botschafter über das Aussenministerium. .. ${ }^{46}$

Aber das nun fiel bei Nettlau weniger gut. Er reagierte für Aussenstehende vielleicht etwas merkwürdig, nicht jedoch für Menschen, die ihn besser kannten: „Es ist sehr schön wenn durch Sozialdemokraten, Kapitalisten und eine Regierung schliesslich diese Kisten vor einer Verschleuderung und Zerstreuung bewahrt würden, es würde mich der Sache wegen freuen und ich wäre dankbar; aber, ich bin doch auch noch da: in solchem Fall müsste ich grade all denen dankbar sein, denen ich nicht freundlich gegenüberstehe und mit denen ich nichts zu tun gehabt habe mein Leben lang. Da könnte ich kein Wort mehr gegen sie schreiben, müsste meine Feder zerbrechen und könnte mich nur recht schnell totessen und verschwinden. Diese Selbstausstreichung meines ganzen Lebens und Wesens kann ich nicht wünschen und wünschen auch meine Freunde nicht."47 Ganz unbegründet war Nettlaus Furcht vor Beschlagnahme nicht. Ende 1922 wurde in Paris nach dem Tode seines Freundes Victor Dave seine bei ihm untergestellte Kollektion als Feindesbesitz eingezogen, ein gleiches Schicksal drohte 1927 einer grossen Anzahl in einem Pariser Depot untergebrachter Kisten, dies wussten jedoch Genossen zu verhindern.

Weder Lehning noch Posthumus waren beruhigt über die Nachrichten von Nettlau. Im Oktober fuhr Posthumus erneut nach Wien. Dieses Mal wurde der Vertrag unterzeichnet, am 28. Oktober 1928. Aber damit begannen erst die Schwierigkeiten. In seinen Erinnerungen hat Nettlau den Verlauf sehr ausführlich beschrieben.

Damals im Café [es war ein Sonntag], als die Kaufsumme erledigt war und - so ungefähr erinnere ich mich (es ist notiert), - dass eine Hälfte nach Erhalten der Pariser Kisten gezahlt würde - für das weitere ist mir die genaue Abmachung entfallen, - da sagte er dann: „da Sie zu diesen Bedingungen verkaufen wollen, so wollen wir das gleich schriftlich fixie-

45 Anthony George Kröller (1862-1941), Mitbegründer der Rotterdamer Handelshochschule, nahm einen wichtigen Platz in der niederländischen und internationalen Handelswelt ein. Die durch seine Frau und ihn erworbene weltberühmte Kunstsammlung bildete den Grundstock des 1938 eröffneten Rijksmuseum Kröller-Müller zu Otterloo.

46 Lehning an Nettlau, ca 22. September, Archiv Nettlau.

47 Nettlau an Lehning, 25. September, Archiv Lehning. Auf den Umschlag von Lehnings Brief machte sich Nettlau folgende Notiz: „Ernste Lage, aber ich muss standhalten!” 
ren", und schrieb eine Erklärung: dass ich unter solchen (praezisierten) Bedingungen verkaufe. Ich schrieb mir das zugleich ab, aber das war dann für ihn auch ein Textexemplar, und er verglich es, unterschrieb beide Exemplare und ich unterschrieb sie auch.

Dann sagte er, recht beiläufig: ,jetzt haben Sie verkauft - das ist der gültige Verkauf." Das gab mir einen Stich [. . . . Ich habe nie etwas verkauft und er war Jurist. Ich war wie vor dem Kopf geschlagen, fasste mich aber, wie im Gebirge im Moment einer akuten Gefahr und war ganz kalt und dachte, jetzt muss ich auf mich schauen. Er mag mein Befremden bemerkt haben und erklärte mir, dass meine Unterschrift absolut bindend sei - der Text war fehlerlos und sagte, dass ich verkaufe, und indem ich das unterschrieb und ihm gab, habe ich verkauft. ${ }^{48}$

Am folgenden Morgen trafen sie sich wieder (stets in Cafés). Posthumus bat Nettlau um den Schlüssel seines Safes im Chancery Lane Safe Deposit in London und um Vollmachten für das Lagerhaus in Paris. Das gab den Ausschlag. Als Nettlau sich kurze Zeit später deutlich machen wollte, was nun genau geschehen war, stellte er fest, in jenem Augenblick definitiv begriffen zu haben: „der Mann will meine Bibliothek!"49

Nun trat Nettlau einen strategischen Rückzug an.

Bei all meinem Bestreben, gefällig und entgegenkommend zu sein, blieb ich hart im Bezug auf den Schlüssel und gab ihn nicht her. Es stellte sich dann, ich weiss nicht mehr wie, nach ganz schroffen Szenen oder sprachlosen Szenen, wo wir beide über neue Auswege brüteten, irgend eine „Formel” ein, wie bei den Diplomaten, die eine Windstille bedeutete, und dann tauchte plötzlich die luminöse Idee auf, dass wir genug geredet hätten, den Gegenstand erschöpft hatten und nun auch einmal von etwas anderem reden könnten. Der Professor wäre noch sitzen geblieben, aber nach gegen dreistündigem Sitzen am gleichen Fleck schlug ich vor, in ein anderes Café zu gehen und die Verkauf- und Schlüsselfrage an der Tür des andern zurückzulassen - ich glaube auf dem Weg war noch Wetterleuchten. Das Café am Schwarzenbergplatz war zuerst überraschend voll und geräuschvoll und wir bekamen gleich späte Abendblätter in die Hand - die ersten

${ }^{4 \gamma}$ Nettlau, Erinnerungen und Eindrücke, a.a.O., S. 187.

49 Mehr als drei Jahre später schreibt Nettlau Lehning über diese Stunden: „und dann wurde mir auf einmal gesagt (ungefähr so und sehr höflich): ,Sie scheinen nicht zu wissen, dass Sie nicht mehr der Besitzer sind. Der Besitzer ist seit gestern die Archivgesellschaft.' Da stürzte ich in einen Abgrund und war wie vor den Kopf geschlagen, aber wie ich es immer in grosser Gefahr getan habe, instinktiv, ich blieb ganz ruhig. Es war wie, als ich einmal in der Mont Blanc Gruppe auf einem steilen Eisfeld ausrutschte und der Spalte zu hinabglitt: ich sagte kein Wort, sah mich heruntergleiten, hackte aber im letzten Moment den Fuss so fest in eine dünne Ritze im Eis, dass er tief einschlug, einen Halt gewann und das war ein Meter vor der Spalte und ich kroch dann sehr langsam aufwărts, dem Felsrand zu. - So war mir damals angesichts des gähnenden Abgrundes ich sollte schon verkauft sein und das jetzige Reden sei nur Höflichkeitssache - die Besitzer können schon verlangen." Nettlau an Lehning, Dezember 1931, Archiv Lehning. 
Blätter in die ich bei all den Caféhausbesuchen einen Blick warf und ich fing dann auch an zu lesen und brachte dem Professor bei, dass man sich selbst schuldig ist, das neueste Abendblatt zunächst durchzusehen. So entstand eine Caesur und nachher wurde von schönen Gegenden gesprochen, von Südwestfrankreich, wo er Dokumente studiert hatte (Cahors), von einigen seltenen alten Büchern, von der Utopiensammlung von John Burns usw.

Gegen Abend ging jeder seines Weges. Nettlau kaufte etwas zu essen, notierte seine Tageserlebnisse in Kurzschrift und kam zu der Einsicht, seine Sammlung überhaupt nicht verkaufen zu wollen. Er schrieb daraufhin eine ,motivierte Ablehnung", steckte diese zusammen mit dem von ihm durchgestrichenen und ungültig erklärten Vertrag und den Fotos von dem Gebäude in Amsterdam in einen Umschlag und hat „dann sehr gut geschlafen”. Den folgenden Tag eilte er zu dem Treffpunkt, auch Posthumus erschien pünktlich. Nettlau hatte eine Erklärung von zwei, drei Zeilen vorbereitet und begann sie zu sagen, während er Posthumus den Umschlag reichte. „Er erstaunte, begriff sofort, erstarrte, presste beide Arme fest an den Körper", Nettlau bekam keine Gelegenheit, ihm den Umschlag zu überreichen, noch ihn Posthumus unter den Arm zu schieben. Er lief davon, aber Nettlau wurde nur durch einen einzigen Gedanken beherrscht: der Umschlag musste in die Hände „des Professors” gelangen. Er eilte zu Fuss zu dem Hotel am Mehlmarkt, wo Posthumus abgestiegen war, bedacht, Vorsprung zu gewinnen. „Kurz das war ein Kunstlauf, der mir von ungezählten Automobilen den Tod oder wenn etwa die jetzige Amsterdamer Verkehrsordnung für noch vorhandene Strassenfussgänger gegolten hätte, Geld- und Gefängnisstrafen in schwindelnder Höhe hätte eintragen können - und meiner Gesundheit mit 63 Jahren hat es gewiss auch nicht genutzt." Aber er kam als Erster an und gab das Päckchen beim Portier ab. Nach Haus zurückgekehrt und erleichtert, endlich allein zu sein, kochte er sich eine grosse Kanne Kaffee, las die Zeitungen der letzten vier Tage und nahm dann die Arbeit auf, ,was so ist, wie wenn man in den Wald geht und dann bald mit sich und seinen Problemen allein ist". Er war wie neu geboren, für ihn war die Angelegenheit erledigt. ${ }^{50}$

Er hatte jedoch die Rechnung ohne den Wirt gemacht. Posthumus hatte den Vertrag bereits einen Tag nach der Unterzeichnung in das Wiener Handelsregister eintragen lassen, und Anfang November teilten Hajo Brugmans und Posthumus namens des Vorstands des Archiefs Nettlau mit, dass man sich nicht mit der Erklärung, er habe den Vertrag annulliert,

${ }^{50}$ Nettlau, Erinnerungen und Eindrücke, a.a.O., S. 188-91. 
zufrieden geben könne. ${ }^{51}$ Einige Tage später trat der Vorstand an Lehning mit der Bitte heran, ob er noch einen letzten Versuch unternehmen wolle, um Nettlau auf seinen Beschluss zurückkommen zu lassen. Sollte Nettlau den festgesetzten Preis zu niedrig finden, könne er einen höheren anbieten. Lehning erklärte sich bereit, aber nach einem dreistündigen Gespräch in Wien liess ihn Nettlau wissen, lieber nicht mehr darüber sprechen zu wollen. Lehning blieb nichts anderes übrig, als am 20. November Posthumus noch von dort aus zu melden, dass alle Mühe vergeblich sei. Er bedauere es, die Angelegenheit anhängig gemacht zu haben, was er auch Nettlau gesagt hätte. ,Als einzige Entschuldigung könne gelten, dass auch Sie fanden, dass sie es wert war."52 Und an Nettlau schrieb er: „Seit ich Ihre Arbeit und Ihre Sammlung kenne habe ich mich dafür interessiert und seit der Zeit, als Sie mich, vor vier Jahren, in Wien, nach der Möglichkeit fragten einer Lösung für das Problem Ihrer Sammlung in Holland habe ich mich mit diesem Gedanken beschäftigt. [. . .] Als Sie den Kontrakt unterschrieben war fast allen Ihren Wünschen vollkommen Rechnung getragen. Um so unbegreiflicher der Strich durch alle Abmachungen."53

Musste es so kommen, fragte sich Lehning einige Jahre später. Hatte Posthumus die Angelegenheit eventuell zu geschäftsmässig, zu juristisch, und er, Nettlau, sie zu gefühlsmässig behandelt? Wäre deswegen vielleicht der bedauerliche Konflikt entstanden. „Oder? - Wäre dieser doch gekommen?" Nettlau stellte es so dar, als ob er mehr oder weniger zu diesem Schritt gezwungen worden wäre, woraus Lehning schloss, dass er dann wohl auch noch nicht dazu bereit gewesen sei: „Vielleicht wollten Sie sich doch nicht von Ihrer Sammlung trennen?"54 Posthumus wollte nun die Angelegenheit einem Rechtsanwalt übergeben. Lehning empfahl ihm den Tolstoianer Dr Franz Kobler, Herausgeber von Gewalt und Gewaltlosig-

51 Kopie Archiv Lehning.

52 Ebd.

${ }^{53}$ Lehning an Nettlau, 25. November 1928, Archiv Nettlau.

${ }^{54}$ Lehning an Nettlau, 6. April 1932, Archiv Nettlau. Als der über den Verlauf der Verhandlungen durch Lehning unterrichtete Roger Baldwin auf dessen Bitte einen sehr guten Freund Nettlaus in Amerika, M. A. Cohn, zu Hilfe rief, schrieb dieser ihm: "Nettlau simply hates like poison to part from his books. They seem to be his wife, children and his very life." (3. Januar 1929, IISG) Im selben Sinn hatte nach ergebnislosen Verhandlungen über den Ankauf der Bibliothek Dr Weil, der Gründer und Finanzier der Gesellschaft für Sozialforschung, des berühmten „Frankfurter Instituts”, an Nettlau im März 1924 geschrieben: „Wir sind wiederholt darauf aufmerksam gemacht worden [Notiz von Nettlau: ,von welchem Denunzianten?] und müssen nach dem Verlauf der bisherigen Verhandlungen auch aus eigener Erfahrung zum Schlusse gelangen, dass Sie selbst vorläufig innerlich noch gar nicht entschlossen sind, die Bibliothek abzugeben, sondern nur mit dem Gedanken daran spielen." Nettlau schrieb hierbei: „Grob zu sein hat er keine Veranlassung. Gut, dass die Sache zuende ist!” Archiv Nettlau. 
keit. Handbuch des aktiven Pazifismus und des Handbuch der Friedensbewegung. ${ }^{55}$ Nettlau beurteilte die Wahl als nicht unfreundlich ihm gegenüber, sie beeinflusste jedoch nicht seinen Standpunkt. Einige Zeit später riet Kobler dem Vorstand des Archiefs ab, Schritte gegen diesen sonderbaren, alten und in der anarchistischen Welt allgemein hochgeschätzten Mann zu unternehmen. Es schiene ihm, meinte er zu Lehning, wie eine Dickens-Affäre, wenn dieser Mann wegen seiner Bibliothek in einen Prozess verwickelt werden würde. Der Vorstand akzeptierte es vorläufig, gab aber Nettlau, sehr zu dessen Verbitterung, trotz seines noch Jahre später wiederholten Drängens, den von ihm unterzeichneten Vertrag nicht zurück.

Im Sommer 1930 besuchte Nettlau Lehning in Paris und bat ihn, in dieser Angelegenheit bei Posthumus zu intervenieren, November 1931 wiederholte er seine dringende Bitte. „Ich höre nichts mehr seit zwei Jahren und habe nur den Wunsch, ein formelles Schlusswort zu hören, dass nicht nach mir etwa gar posthume Schwierigkeiten entstehen. Das halte ich für menschlich." Als Lehning kurz darauf Posthumus sprach, sagte ihm dieser, dass er die Sache seit einiger Zeit ruhen liesse, „um so mehr da die anderen Herren diesen Punkt nur sehr ungerne noch auf die Tagesordnung der Vorstandssitzungen des Economisch-Historischen Archivs sähen!" Was aber eventuelle ,posthume Schwierigkeiten” betraf, erkundigte sich Lehning neugierig: ,Es ist wohl zu unbescheiden zu fragen ob Sie inzwischen eine andere und definitive Regelung zu einer befriedigenden und dauernden Konservierung getroffen haben?"56 In seiner Antwort bat Nettlau um menschliches Verständnis: „Wenn ich mich geirrt habe, so hat vorher auch der Herr Professor geirrt, indem er sich zu sehr exponierte und mir dann zu sehr zusetzte und dann sich nicht ,blamiert' haben wollte, wovon doch keine Rede war." Er fand es eine höchst ungerechte Angelegenheit und meinte, dass sich derjenige, der alles in Gang gesetzt hätte, nun auch für ihn einsetzen müsse. In diesem Sinn schrieb er Lehning im April 1932: „Durch Sie (Ihren besten Willen) bin ich doch eigentlich zu der ganzen Sache gekommen, indem ich - ohne dass ich Sie für etwas verantwortlich halten würde (selbstverständlich!) - eben Ihrer Person, d.h. Ihrer Verbindung mit unseren Ideen und Freunden, meine unbedenkliche Zutraulichkeit, um mich so auszudrücken, zu den Archivleuten, dem Professor, verdanke. Ohne dies wäre ich weitaus zurückhaltender gewesen und es wäre wohl zu der Unterschrift nicht gekommen.

55 Von Lehning rezensiert in Die Internationale (Berlin), Juli 1929. Er stand mit Kobler seit 1925 in Verbindung.

56 Lehning an Nettlau, 27. November 1931, Archiv Nettlau. 
[...] Also in diesem Sinn, da Sie am Anfang der Sache standen, halten Sie sich doch ein bischen dazu angeregt und eingeladen auch für das: Ende gut, Alles gut, zu sorgen." 57 Erneut versuchte Lehning, Posthumus umzustimmen, vergeblich, er blieb unnachgiebig und fand übrigens, dass Arthur seltsame Freunde hätte!

So endete Posthumus' erster Versuch, die Sammlung zu erwerben, für die, um, so Nettlau, ,,einmal pompös zu reden, schon mehr Städte in Frage kamen als für den Geburtsort von Homer, nämlich in ungeordneter Reihenfolge [. . . : London - Oxford - Amsterdam - Heidelberg - Berlin Wien - Sophia - Moskau (Offert) - Basel - Genf - Barcelona - New York - Ann Arbor, Wisconsin - Buenos Aires - Tonnerre, Yonne, das sind 15 gegenüber nur 7 Geburtsorten von Homer, und Jerusalem (Offert) macht 16."58 Lehnings Beziehungen zu Nettlau und Posthumus wurden übrigens durch die Vorgänge nicht getrübt. Nettlau schickte ihm im Dezember 1928 eine vorgedruckte Neujahrskarte, derem Text „Glückliche Stunden im neuen Jahr” er ,wünscht Ihnen, hoffentlich durch jene Angelegenheit nicht ganz von Ihnen getrennt, M. Nettlau" hinzugefügt hatte. Auch arbeitete er u.a. mit an dem von Lehning redigierten Blatt Grondslagen, dem theoretischen Organ der holländischen Anarchosyndikalisten. ${ }^{59}$

Ab 1933 wurden erneut, diesmal von verschiedenen Seiten, Anstrengungen unternommen, Nettlaus Bibliothek in Holland in Sicherheit zu bringen, denn nicht nur in Deutschland, auch in Österreich machte sich der Faschismus immer unverhüllter breit. Am 4. März 1933 gab die Selbstausschaltung des Parlaments Dollfuss die Gelegenheit, die Demo-

57 Nettlau an Lehning, April 1932, Archiv Lehning.

58 Nettlau, Erinnerungen und Eindrücke, a.a.O., S. 196. Was übrigens Moskau betraf, versuchte Rjazanov, der Gründer und Direktor des dortigen Marx-Engels-Instituts, 1925 die Sammlung Nettlaus durch Vermittlung von Carl Grünberg zu erwerben. Über die Kaufsumme würde man sich zweifellos einig werden können, ausserdem würde man Nettlau in Moskau ,eine geeignete Wohnung zur Verfügung [stellen], sowie einen Arbeitsraum, wo Sie unter Benutzung des im Marx-Engels-Institut, sowie in allen russischen Archiven vorhandenen Materials Ihr grosses Werk über Bakunin in vollster Ruhe vollenden könnten". Pollock an Nettlau, 19. August 1925, Archiv Nettlau. Rjazanov wurde 1931 von Stalin entlassen, verhaftet und danach ,administrativ" verbannt. Er starb 1938, wo und unter welchen Umständen ist nicht bekannt.

59 Amsterdam 1932-35 (Reprint 1979). In den Jahren 1927 bis 1929 ist sein Name auch unter den Mitarbeitern der von Lehning redigierten i $10 \mathrm{zu}$ finden, einer Monatsschrift für moderne Architektur, Kunst, Literatur und Politik (Internationale revue, i 10, Amsterdam 1927-29, Reprint 1979). Nettlau verstand nicht viel von moderner Kunst. Kandinskys Werke liessen ihn nach dem Kaleidoskop seiner Kindheit zurückverlangen, und seit er in i 10 eine Abbildung von Mondriaans Atelier gesehen hatte, verstand er, warum der Künstler nicht mehr Inspiration besass. Nettlau an Lehning, 31. Januar 1927. 
kratie funktionsunfähig zu machen; am 15. März verhinderte Polizeigewalt die Wiedereröffnung des Parlaments und am 31. März folgte die Auflösung durch die Regierung. Nettlau schien offenbar den Ernst der Lage nicht ausreichend einzuschätzen, denn Rudolf Rocker schrieb ihm im September 1933, erstaunt über seine „unerschütterliche Hoffnungsfreudigkeit angesichts der furchtbaren Lage in Deutschland" zu sein. Wenn in einem Land die Reaktion weitgehende extreme und unmenschliche Formen annehme, herrsche allgemein die Auffassung, dass so ein Regime es nicht lange machen würde. „Als vor zehn Jahren unsre 21 aus Russland ausgewiesene Genossen in Berlin ankamen, war nicht einer unter ihnen, der nicht fest davon überzeugt war, dass das bolschewistische Regime seinen Höhepunkt überschritten und eine Änderung der Dinge in Bälde zu erwarten sei. [. . .] Heute stehen wir vor der nationalen Revolution in Deutschland, die an Gemeinheit, Schmutzigkeit, Infamie und Unmenschlichkeit alles übertrifft, was wir bisher auf diesem Gebiete erlebt haben." Und er fügte hinzu, Hitler habe im Inland vorläufig nichts zu befürchten, ,denn in Deutschland gab es bisher keinen Kanzler, der sich einer solchen Popularität erfreute" ${ }^{60} \mathrm{Im}$ selben Monat schrieb Posthumus Lehning beunruhigt über seinen „Wiener Freund”. Er wäre bereit, dessen

60 Rocker an Nettlau, 27. September 1933, Archiv Nettlau. Bereits drei Jahre vorher hatte er ihm geschrieben: „Vorausgesetzt, dass wir überhaupt noch lange mit unsrer Arbeit ungestört angehen können; denn das Feuer des Fascismus brennt uns auf den Fingernägeln, und Gnade uns Gott, wenn diese Bande siegt. Italien wird der reinste Kindergarten gegen ein offenes fascistisches Deutschland sein." (30. Dezember 1930, ebd.) Der Brief vom September 1933 ist ein bewegendes Zeugnis eines Menschen, der nur mit knapper Not direkt nach dem Reichstagsbrand am 27. Februar der Barbarei der Nationalsozialisten mit seiner Familie zu entflüchten wusste. Er liess seine Bibliothek zurück, die vernichtet wurde, er liess aber auch einen seiner besten Freunde, Erich Mühsam, zurück, der am selben 27. Februar eine Zugkarte nach Prag gekauft hatte, zuhause noch Koffer packen wollte, dort aber verhaftet und nach unvorstellbar grausamen Misshandlungen am 9. Juli 1934 im KZ Oranienburg ermordet wurde.

Rocker focht Nettlaus auf die Dreyfussaffäre verweisende Überzeugung an, dass das, was in Deutschland geschah, auch in jedem anderen Land geschehen könne. Aber wo, fragte Rocker, wurden damals wehrlose Opfer gefoltert und in Konzentrationslager verschleppt; wo ist es jemals geschehen, dass eine Regierung einen Judenboykott organisierte? ,Wo hat man gesehen, dass tausende von Privatbibliotheken zerstört wurden, dass gebildete Hooleganes die ,undeutschen' Bücher auf öffentlichen Scheiterhaufen verbrannt haben und dass sich Hunderte von deutschen Professoren dazu hergaben, für die Regierung die undeutschen Bücher aus den öffentlichen Bibliotheken auszumerzen? Zeigen Sie mir irgend ein anderes Land, in dem man einer solchen Schar von intellektuellen Halunken begegnen kann. [...] In Frankreich fand sich ein Zola, der den Mächten der Reaktion sein ,Ich klage an!' entgegenschleuderte. In Deutschland aber schreibt ein Gerhard Hauptmann einen Prolog zu einer Horst-Wessel-Aufführung [. . .]. Es gab und gibt Reaktionäre in allen Ländern, aber eine solche Kotflut wie heute in Deutschland, einen solchen Triumph des Untermenschentums hat die Geschichte noch in keinem Lande gesehen." 
Bibliothek ohne irgendwelche Bedingungen in Amsterdam unterzustellen, selbst die Frachtkosten wolle er übernehmen, „man muss nun einander helfen!" Bereits seit 1930 beriet Lehning den in diesen Jahren grosse Aktivitäten entfaltenden Posthumus beim Ankauf von Bibliotheken für das Archief und nach 1932 für die Economisch-Historische Bibliotheek, die letzteren Sammlungen sollten später den Grundstock des Internationalen Instituts für Sozialgeschichte bilden.

Im Sommer 1933 hatte Fritz Brupbacher, Arzt in Zürich und seit 1929 mit Nettlau befreundet, einen alarmierenden Brief über dessen hoffnungslose finanzielle Lage an verschiedene anarchistische Genossen geschickt: „wenn seine Freunde ihn nicht ernähren können wird Max Nettlau Hungers sterben. Das ist ganz wörtlich zu nehmen." Er ergänzte, dass sich zur Zeit (den Krisenjahren) wohl weder für die Bibliothek noch für die Manuskripte Nettlaus ein Käufer finden lassen würde. Da Brupbacher auch holländischen Genossen geschrieben hatte, gelangte der Brief auf Umwegen in die Hände des Chefredakteurs von De Syndicalist, des Genossen und Freundes Arthur Lehnings, des Anarchosyndikalisten Albert de Jong. Er antwortete Brupbacher im November, dass man in den Niederlanden bereits an viele appelliere, geflüchtete deutsche Genossen finanziell zu unterstützen. Er würde sich aber fragen, ob Nettlau nicht allmählich Massnahmen ergreifen müsse, um seine Bibliothek vor dem Untergang zu retten. Die beste Lösung wäre, wenn er mit ihr nach Holland käme. ,Hier ist eine gute ökonomisch-historische Bibliothek, mit welcher wir zusammenarbeiten für die Bibliothek von weiland Domela Nieuwenhuis." Der Direktor habe ihm erzählt, dass bei Nettlaus Tode ein Teil seiner Bibliothek an die Preussische Staatsbibliothek und der Rest verloren gehen würde. Er, der Direktor, hätte bereits mehrere Male mit Nettlau darüber unterhandelt, er könnte ihm eine Leibrente von fl 1000 bis 1200 zusichern. Man fände eigentlich, dass Nettlau das akzeptieren könne. „Dieser Meinung war auch Genossin [Emma] Goldman, mit der ich vor zwei Tagen sprach." Die durch Albert de Jong informierte Bibliothekarin der Economisch-Historische Bibliotheek, Dr Jane de Iongh, erkundigte sich kurz darauf bei Brupbacher, welche Schritte man unternehmen könne. ${ }^{61}$ Brupbacher, der wahrscheinlich nie von Nettlau etwas über die Unterhandlungen 1928 mit Amsterdam gehört hatte, teilte ihm begeistert den Vorschlag mit: „Mir scheint, die Sache wäre glänzend!” Nettlaus Antwort habe ich nicht gefunden, aber der Inhalt lässt sich aus Brupbachers folgendem Brief erraten: „Es tut mir leid Sie in Trauer versetzt zu haben durch meinen Vorschlag mit Holland."62

61 De Jong an Brupbacher, 24. November 1933; De Iongh an Brupbacher, 9. Dezember. Archiv Brupbacher, IISG. 
Die Situation verschlechterte sich zunehmend, nicht zuletzt in Österreich. Am 12. Februar 1934 brach dort der erste bewaffnete Aufstand in Europa gegen den Faschismus aus, den Dollfuss blutig niederschlagen liess. „Zwei Tage später”, so Nettlau, „erschien einer der Brüder Nacht, der Amerikaner war, und war bereit meine wesentlichsten Papiere und Manuskripte in die Schweiz zu bringen [. . . I. Ich lehnte ab". ${ }^{63}$ Er beharrte auf dieser Weigerung, als im Laufe des Frühjahrs ein erneuter Versuch unternommen wurde, seine Sammlung in Sicherheit zu bringen, diesmal durch Annie Adama van Scheltema, die spätere Bibliothekarin des IISG, damals noch Mitarbeiterin der Economisch-Historische Bibliotheek. Über Christiaan Cornelissen, den Nettlau seit Jahrzehnten kannte und dem er auch einen Teil seiner Sammlung anvertraut hatte, versuchte sie, mit ihm Kontakt zu bekommen. Aber Nettlau teilte Cornelissen mit, gerade dank seines Bruches mit Posthumus habe er seit 1928 noch fast sechs Jahre lang mit Hilfe seines Materials intensiv wissenschaftlich arbeiten können, ,au lieu, peut-être, de me promener et de ne faire rien, si j'avais cédé et si l'argent avait pris la place de l'intellectualité". (Sein Argument war nicht besonders stichhaltig, er musste wissen, dass es Posthumus nur begrüsst hätte, wenn er sein Material, so wie es übrigens auch später geschah, in Amsterdam bearbeitet hätte.) Cornelissen müsse seine Briefpartnerin schon auf den Herbst vertrösten, aber ,il est peu probable que quelque chose soit fait avant ma mort". ${ }^{64}$ Einige Monate später versuchte es Annie Scheltema erneut, wiederum über Cornelissen, aber Nettlau antwortete ihm Ende Januar 1935, unter keinen Umständen mit ihr über die alte Affäre sprechen zu wollen: „Je ne veux qu'être laissé tranquille et je réclame cela absolument." 65

In der Zwischenzeit ging ein jahrelang gehegter Wunsch von Posthumus in Erfüllung: die Gründung eines Instituts, das sich auf dem Gebiet der Sozialgeschichte, insbesondere der Geschichte des Sozialismus und der

62 Brupbacher an Nettlau, 3. und 17. Dezember, Archiv Nettlau.

${ }^{63}$ Nettlau, Erinnerungen und Eindrücke, Zweite Serie, Heft 7, S. 164. Max, bekannt unter dem Namen Max Nomad, ist der jüngere Bruder von Siegfried Nacht.

64 Cornelissen an Annie Scheltema, 24. Juni 1934, IISG. Christiaan Cornelissen (1864-1942), Organisator der ersten, 1893 gegründeten niederländischen Gewerkschaftszentrale, des revolutionär-syndikalistischen Nationaal Arbeidssecretariaat. 1892 erschien von ihm eine Ubersetzung des Kommunistischen Manifests, die erste in niederländischer Sprache. Ab Mai 1898 lebte er in Frankreich. Lehning veröffentlichte über ihn einen biographischen Beitrag im Mededelingenblad Sociaal-Historische Studiekring (Amsterdam), Nr 6 (1955), und gab in der Nr 10 (1957) einige Fragmente aus seiner Autobiographie heraus.

65 Nettlau an Cornelissen, 31. Januar 1935. Diesen Brief legte Cornelissen seinem Brief vom 30. März an Annie Scheltema bei. IISG. 
Arbeiterbewegung spezialisieren sollte. Er fand Unterstützung bei dem Direktor der Centrale Arbeiders-Verzekerings- en Depositobank in Den Haag, dem Zionisten Nehemia de Lieme, einem Mann mit grossem Interesse an den Wissenschaften. ${ }^{66}$ In den Statuten der Centrale, wie die Bank kurzweg genannt wurde, war festgelegt, dass ihre Gewinne die kulturelle und ökonomische Entwicklung der Arbeiter fördern sollte. Durch Zusammenarbeit der Centrale mit dem Archief konnte am 25. November 1935 die Stiftung „Het Internationaal Instituut voor Sociale Geschiedenis” ins Leben gerufen werden.

Die ersten Jahre des IISG sollten im Zeichen einer grossartigen, durch die Machtübernahme der Nationalsozialisten immer notwendigeren Rettungsaktion stehen und durch den Erwerb der aussergewöhnlichsten Archive und Bibliotheken gekrönt werden. Die Stadt Amsterdam stellte als Gebäude die ehemalige Mädchenoberschule auf der Keizersgracht 264 zur Verfügung. Umbau und Einrichtung gingen zu Lasten der Centrale. Bereits im Dezember 1935 beschloss der Vorstand die Gründung einer Filiale in Paris, hauptsächlich, um Ankäufe in Frankreich zu erleichtern. Zu diesem Zweck wurde 1936 eine Etage in der Rue Michelet $\mathrm{Nr} 7$ gemietet. In den wenigen Vorkriegsjahren sollte das Institut von 1935 bis Mai 1940 fieberhafte Aktivitäten entwickeln. Angekaufte Bibliotheken und Sammlungen wurden sogleich durch systematische Aufstellung in Regalen zugänglich gemacht. Unterdessen erschienen zwei Periodika, das Jahrbuch International Review for Social History und das viermonatliche Bulletin of the International Institute for Social History, Ausgaben, die nicht zu einem geringen Teil durch Beiträge der fünf wissenschaftlichen Mitarbeiter ${ }^{67}$ ermöglicht wurden, die auch alle an der Vorbereitung einer umfangreichen Quellenausgabe über die Erste Internationale Arbeiter-Assoziation (1864-77) mitarbeiteten.

Die erste Bibliothekarin des IISG war die bereits erwähnte Annie Adama van Scheltema-Kleefstra (1884-1977), Witwe des 1924 verstorbenen sozialdemokratischen Dichters Carel Adama van Scheltema. Durch ihn lernte sie die Führer der niederländischen Sozialdemokratie kennen,

66 Er starb achtundfünfzigjährig im Juni 1940.

67 A. Lehning, B. Nikolaevskij, A. J. C. Rüter, B. Sapir und H. Stein. Ein Pressebericht von Anfang 1936 meldete, dass ,,das Institut durch regelmässige Publikationen zu einem genaueren Studium und einer grösseren Kenntnis des Tatsachenmaterials beizutragen hofft, das die Basis der anscheinend so verwirrenden Struktur unserer gegenwärtigen Gesellschaft bildet". Viele Besprechungen fanden zur Frage der anzuwendenden Bibliothekssystematik statt. Auf Lehnings Bitte teilte ihm Nettlau ausführlich seine Auffassung über eine gute Systematik mit, u.a. schrieb er: „Auch Bücher sind Wesen, die man von unten nach oben gruppieren kann, aber nicht von oben nach unten einordnen soll." 
ebenso seine Freunde aus dem Studentendisput "Clio", unter ihnen Posthumus, der ihr 1932 die Leitung der damals noch kleinen sozialhistorischen Abteilung der Economisch-Historische Bibliotheek anvertraute. $\mathrm{Er}$ sorgte auch für ihre Ernennung zur Archivarin der Sociaal-Democratische Arbeiderspartij, um ihr niedriges Gehalt aufzubessern. Als Bibliothekarin hat sie viel erreicht, weniger für die Erschliessung des Bestandes (für das Bibliothekswesen selbst fehlte ihr das Interesse), als für die Mehrung des Besitzes. „Ich wurde damals [1934] ein leidenschaftlicher Sammler”, wird sie später in ihren Erinnerungen schreiben. ${ }^{68}$ Mit grosser Hingabe und tatkräftigem Einsatz widmete sie sich dieser Sache, die sie als ihre Lebensaufgabe begriff. Vor dem Krieg wurde Annie Scheltema mehrmals von Posthumus ins Ausland geschickt, um die angekauften Sammlungen, u.a. aus Nazi-Deutschland, nach Amsterdam zu bringen. Sie schaffte es stets mit grossem Flair, manchmal unter bedrängtesten Umständen. Auch bei dem Erwerb von Nettlaus Sammlung sollte sie keine unwichtige Rolle spielen, aber dafür müssen wir etwas in der Zeit zurückgehen.

Februar 1935 berichtete Lehning Nettlau aus Barcelona, ihm seien während eines kurzen Aufenthaltes in den Niederlanden sehr günstige Arbeitsverhältnisse in Aussicht gestellt worden, darüber würde er später noch schreiben (es handelte sich natürlich um das im Gründungsstadium befindliche IISG), er habe aber dort auch mit einem grossen Verlag über die Herausgabe von Nettlaus Manuskripten gesprochen. Über den Namen liess er ihn im Ungewissen, es war nämlich der Verlag Brill und sein Gesprächspartner Posthumus, damals ein Mitglied des Aufsichtsrats. Nettlau war begeistert. ${ }^{69}$ Im Mai desselben Jahres kam er auf Besuch in Las Planas bei Barcelona. Lehning arbeitete nach seinem Fortgang aus Berlin März 1933 als Sekretär der anarchosyndikalistischen Internationale erst in Madrid, dann seit dem Sommer 1934 in Barcelona. Beinahe zur

68 A. Adama van Scheltema-Kleefstra, Herinneringen van de bibliothecaresse van het Internationaal Instituut voor Sociale Geschiedenis, Amsterdam o.J. Diese Erinnerungen hat sie 1968-69 in meinem Beisein auf Band diktiert. Sie erschienen anlässlich ihres 93. Geburtstages am 25. Februar 1977 in einer kleinen Auflage und wurden als „Herinneringen van de bibliothecaresse van het Internationaal Instituut voor Sociale Geschiedenis" im Tijdschrift voor Sociale Geschiedenis, Jg. 4 (1978), S. 141-76, nachgedruckt. Eine deutsche Übersetzung erschien im Mitteilungsblatt des Instituts zur Geschichte der Arbeiterbewegung (Bochum), Nr 4 (1979), S. 7-44. Zu gewissen Textabweichungen, bzw. -änderungen vgl. Anm. 64 in der ursprünglichen niederländischen Fassung meines Artikels.

${ }^{69}$ Er bot Lehning vier Manuskripte an, die die Geschichte des Anarchismus von 1886 bis 1914 und manchmal noch darüber hinaus umfassten. Der erste Teil hiervon ist 1981 als Band IV der Geschichte der Anarchie u.d.T. Die erste Blütezeit der Anarchie: 1886-1894 im Topos Verlag, Vaduz, erschienen. 


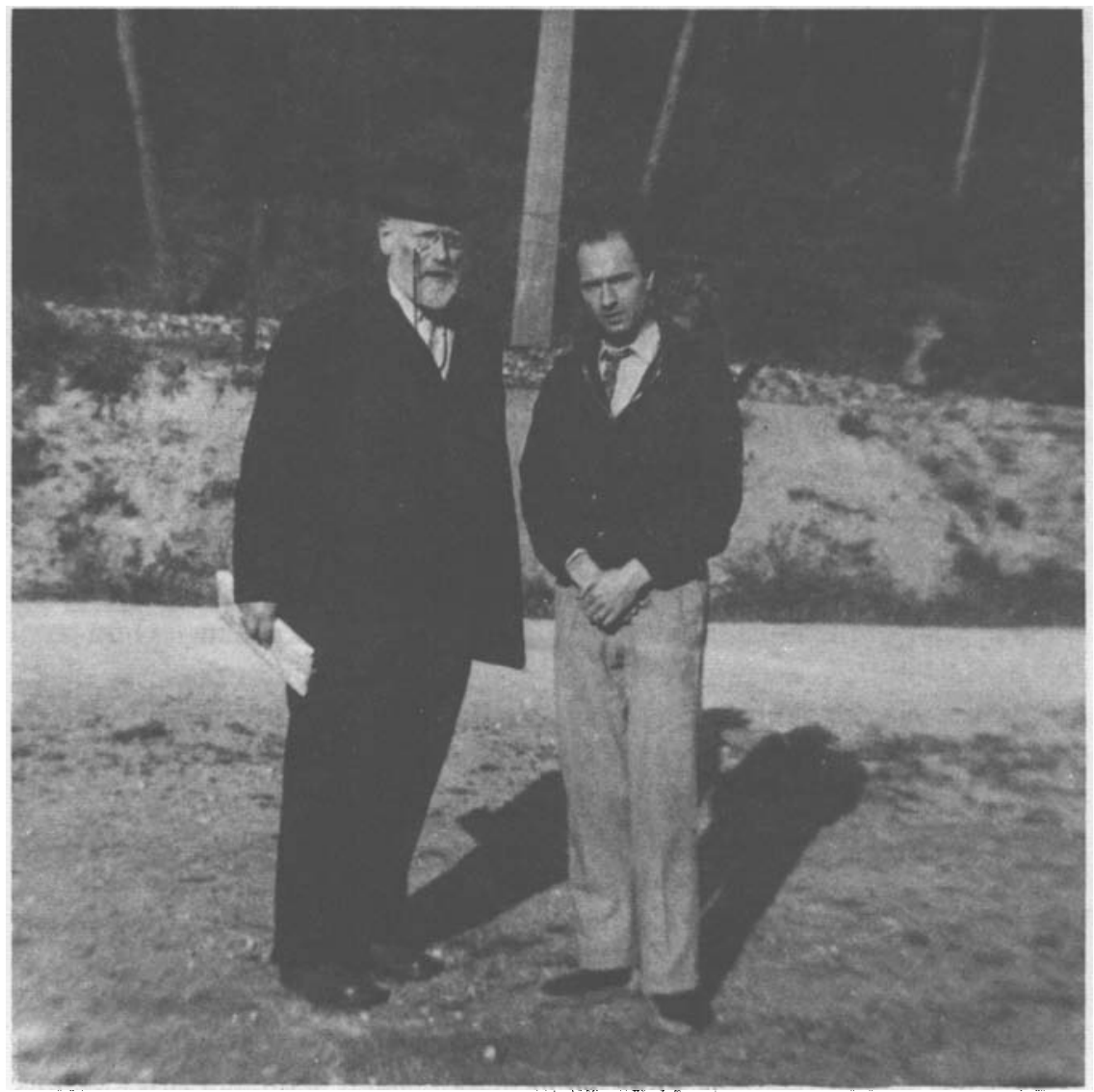

Nettlau und Lehning in Las Planas, Mai 1935

gleichen Zeit bat Posthumus Lehning, Nettlau mitzuteilen, dass das zu gründende IISG ohne jede Gegenleistung bereit sei, für die Unterbringung seiner Sammlung einige Räume zur Verfügung zu stellen. Lehning müsse nur als ,voraussichtlicher” Chef der Abteilung Anarchismus auftreten, und sollte sich Nettlau nach der Position von Posthumus im Institut erkundigen, müsse er eben antworten, dass er nicht Direktor sei, was damals durchaus der Wahrheit entsprach, da das IISG erst im November offiziell gegründet wurde. Nettlaus Reaktion auf diesen Vorschlag ist nicht bekannt.

Dann erscheint schliesslich in dieser Angelegenheit der russische Historiker und Menschewist Nikolaevskij auf der Bildfläche, den Posthumus 
Januar 1935 eingestellt hatte, um das Parteiarchiv der Sozialdemokratischen Partei Deutschlands zu inventarisieren. Boris Ivanovič Nikolaevskij wurde am 20. Oktober 1883 in der Nähe von Ufa als Sohn eines orthodoxen Priesters geboren. Wegen revolutionärer Aktivitäten verbrachte er 31 Monate in zaristischen Gefängnissen und wurde danach sieben Jahre verbannt. Nach der Februarrevolution gehörte er als Delegierter des Allrussischen Sowjets der Arbeiter-, Bauern- und Soldatendeputierten der Kommission an, die mit der Untersuchung der Archive der russischen Geheimpolizei beauftragt war. Im Mai 1921 verhaftet und nach einem Hungerstreik Februar 1922 aus Russland ausgewiesen, war er auf Bitte des Direktors Rjazanov von 1923 bis 1930 Korrespondent des Moskauer Marx-Engels-Instituts in Berlin. Im Sommer 1936 wurde er zum Direktor der IISG-Filiale in Paris ernannt. „Ihm ist zu danken”, schreibt Lehning, „dass das Institut Archive von unschätzbarem Wert erwerben konnte, deren Bedeutung viele der übrigen Sammlungen übertreffen."70 $\mathrm{Zu}$ dem Aussergewöhnlichsten, was das IISG auch dank Nikolaevskijs besitzt, gehört das 1938 gekaufte historische Archiv der SPD, zu dem u.a. der schriftliche Nachlass von Marx und Engels, ${ }^{71}$ das Archiv des Londoner Generalrats der Ersten Internationale, sowie die Archive von Moses Hess, August Bebel, Julius Motteler und Eduard Bernstein zählen.

Durch sein Interesse für Bakunin war Nikolaevskij schon früher mit Nettlau in Kontakt gekommen, den er 1925 zum ersten Mal im sozialdemokratischen Parteiarchiv in Berlin traf. Er hatte dort eine Etage höher „das Archiv seiner eigenen Richtung”, wo Nettlau nie gewesen ist, „da er mich nicht einlud [...]. Er war übrigens autonom, Parteimensch nur innerlich, historischer Verehrer von Marx [...]. Er [förderte] vielleicht mehr altes verstecktes an den Tag als irgend ein anderer damals in Deutschland, Professor Gustav Mayer allein ausgenommen."72 Im August

70 Lehning, ,Michael Bakunin und die Geschichtsschreibung”, a.a.O., S. 43.

71 Ausser Tausenden Seiten Manuskripte enthält der Nachlass die aus 1542 Briefen bestehende Korrespondenz zwischen Marx und Engels sowie 4400 an sie gerichtete Briefe Dritter.

${ }^{72}$ Nettlau, Erinnerungen und Eindrücke, Erste Serie, Heft 15, S. 49-50. Am 21. November 1924 hatte Alexander Berkman an Nettlau geschrieben: „Today I write to you on business, very important. It is in behalf of the Russian Menshevik Nikolayevski, who is interested in revol. archives. $\mathrm{He}$ is an old comrade and responsible man. Just now he has been authorised to collect the archives in re Marx and Engels, and the other day he took over the archive of Bernstein." Er wollte wissen, ob Nettlau bestimmtes Material hätte. Zwei Wochen später reagierte Berkman am 8. Dezember auf Nettlaus Antwort: „As to Nikolayevsky, he tells me that he has nothing in common with the Russian Government editions, but that he is or will work with Riasanov's institution." Nettlau merkte hierzu an: "I will have nothing to do with Nik. M.N." Archiv Nettlau.

Alexander Berkman (1870-1936), russisch-amerikanischer Anarchist, verbrachte nach 
1935 besuchte Nikolaevskij Nettlau in Wien und berichtete Posthumus Ende September nicht unzufrieden über dieses Treffen. Er habe es klüger gefunden, nicht zu erzählen, dass er bereits auf dem IISG arbeiten würde, er kam sozusagen, um mit Nettlau über Bakunins Aufenthalt in Dresden zu sprechen. „Er ist jetzt 70 Jahre alt und im Jahre 1937 wird er das 50-jährige Jubiläum seiner Arbeiten über Bakunin feiern können." 73 „Da stand ihm und mir der Mund von Bakunin nicht still [...]. Wir waren durchaus nicht der gleichen Meinung, aber Marx spielte da gar keine Rolle dabei", schrieb Nettlau später in seinen Erinnerungen. Sie wären sieben Stunden zusammen durch die Gegend seiner Geburt gewandert, und er hätte bedauert, dass so viele alte Bäume nicht mehr stünden. ${ }^{74}$ „Er war selbst sehr gerührt und unsere Unterhaltung war sehr intim", berichtete Nikolaevskij. Nettlau bekannte ihm einen lang gehegten Wunsch, die Gründung eines sozialistischen Instituts, in dem alle zusammenarbeiten könnten. Nikolaevskij ergriff diese Gelegenheit, um über das Institut in Amsterdam zu sprechen. Nettlau erzählte ihm daraufhin von den Unterhandlungen 1928, deren Ausgang er nie bedauert hätte, denn er habe noch lange Jahre mit seiner Bibliothek arbeiten können, doch nun würde er alt und wäre sehr beunruhigt über die politische Lage. „Wenn Prof. Posthumus jetzt sein Angebot erneuern würde, würde ich mich nicht negativ dazu stellen." Er wollte jedoch nicht selbst die Initiative ergreifen, würde aber Nikolaevskij die Vollmacht geben, Posthumus seine Worte zu überbringen.

Vierzehn Tage später drängte Nikolaevskij Posthumus, man müsse sich beeilen, er erwarte noch diesen Winter den Kriegsausbruch. „Nettlau

einem misslungenen Attentat auf den amerikanischen Fabrikdirektor Henry Clay Frick vierzehn Jahre im Zuch thaus, davon zehn Jahre in einer Isolierzelle; vgl. sein Buch Prison Memoirs of an Anarchist (1912, deutsch u.d.T. Die Tat, Berlin 1927). 1919 wurde er mit vielen anderen, unter ihnen Emma Goldman, nach Russland deportiert. Nach dem Matrosenaufstand in Kronstadt 1921 verliess er Russland und kritisierte die Sowjetunion in The Russian Tragedy (1922), The Kronstadt Rebellion (1922) und The Bolshevik Myth (1925).

${ }_{73}$ Sein dieses Thema behandelnder Artikel erschien im Band 1 (1936) der International Review for Social History unter dem Titel „M. A. Bakunin in der ,Dresdner Zeitung' (Eine Episode aus der Geschichte des politischen Kampfes in Deutschland in den Jahren 1848/49)".

${ }^{74}$ Nettlau, Erinnerungen und Eindrücke, a.a.O., S. 51. Während eines Spaziergangs in derselben Gegend um Neuwaldegg hatte Nettlau einem amerikanischen Freund 1922 ebenfalls eine Stelle im Wald gezeigt, wo man aus Mangel an Brennholz eine Gruppe prächtiger alter Bäume gefällt hatte. Nettlau war über das, was er „Vandalismus” nannte, sehr entrüstet. „Er hatte buchstäblich Tränen in den Augen, als er mir die hunderte von alten Baumstümpfen zeigte, die melancholisch aus der Erde hervorragten." Rocker, Max Nettlau, S. 209. 
selbst versteht es sehr gut und das ist auch eine der Ursachen, weshalb er psychologisch schon vollständig zum Abschluss des Abkommens mit Ihnen vorbereitet ist." Er habe inzwischen mit ihm über Annie Scheltema gesprochen und ihn auf ihren Besuch vorbereitet. Er meine, dass es gut wäre, wenn sie Nettlau ein fertiges Konzept des Vertrages vorlegen könne und auch die Vollmacht hätte, den Vertrag in Wien zu zeichnen. Selbst schrieb er kurz darauf Nettlau, dass er das Angebot, für das Institut zu arbeiten, angenommen habe (was in Wirklichkeit bereits Monate früher geschehen war) und ermunterte Nettlau, dasselbe zu tun. ${ }^{75}$

An einem der letzten Oktobertage 1935 kam Annie Scheltema bei Nettlau an. Auf ihre Bitte schrieb er nun seine Bedingungen auf elf Folioseiten, mit denen sie zu ihrem Hotel ging, um mit Posthumus zu telefonieren. Sie las ihm das Dokument vor und empfahl, es als Vertrag anzusehen, womit sich Posthumus einverstanden erklärte. Zurück bei Nettlau, stellte sie ihm die Frage: „Herr Doktor, Sie haben nun alles niedergeschrieben was Sie als Bedingungen für den Verkauf Ihrer Sammlung sehen, weshalb sollten wir diese elf Seiten nicht als Kontrakt betrachten und beide unterzeichnen?” „Er fand das”, schreibt Annie Scheltema, ,eigentlich einen guten Vorschlag. Er zündete seine Petroleumlampe an und legte die Seiten vor sich. [...] Ich war sehr beeindruckt, er unterzeichnete jedes Blatt zuerst, ${ }^{76}$ danach ich, und dann bat er: ,Gehen Sie nun bitte gleich fort und kommen Sie dann morgen vor Ihrer Abreise noch eben bei mir vorbei.' So geschah es. Ich versprach ihm, dass ich so gut wie möglich für alles sorgen würde und verliess ihn, einsam und deprimiert."77 „Es ist nun geschehen (nach dem heutigen erhaltenen Dokument)", teilte er Brupbacher kurz darauf mit. Er führte die drei Gründe auf, die ihn zu diesem Schritt veranlasst hatten: auf Anraten seines Arztes müsse er vom Petroleum- auf einen Kohleofen überwechseln, ${ }^{78}$ sein Hauptwerk hätte er beinahe abgeschlossen, finanziell wäre er am Ende. „Die holländische Dame” sei am 9. November nach Amsterdam zurückgekehrt. „Sie ist munter, weil sie die Sammlung kriegt und ich bin das Gegenteil, weil ich sie verliere." Die Bedingungen der UUbereinkunft seien dieselben wie die

75 Nikolaevskij an Posthumus, 28. September und 12. Oktober 1935, IISG.

${ }^{76}$ Dies handgeschriebene Dokument ist bis heute noch nicht gefunden, auf dem IISG befindet sich aber eine maschinenschriftliche Fassung, datiert „Wien, 1. November 1935”, in der es u.a. heisst: „Dieser Entwurf zeigt meine volle Bereitwilligkeit in dieser Sache zu einem zufriedenstellenden Abschluss zu gelangen."

77 Adama van Scheltema, ,Herinneringen van de bibliothecaresse”, a.a.O., S. 147-49.

78 Einen Monat später teilte er Brupbacher begeistert mit, dass der Ofen geliefert worden war, und gab eine minuziöse Beschreibung seines Aussehens. 
von 1928, zuzüglich der durch einen Genossen ${ }^{79}$ bezahlten Transportkosten und einer Kurs-Garantie für die Hälfte der Kaufsumme. Man solle noch nicht darüber sprechen, nur seine Freunde, die ihn bis dahin finanziell unterstützt hätten, habe er es mitgeteilt. ${ }^{80}$

Aus Ascona trafen Mitte November 221 Kisten in Amsterdam ein, danach folgten Sendungen aus München, Wien und Paris. Es war ein grosses Ereignis. Posthumus, der sich gerade im Ausland aufhielt, liess wissen, dass man mit dem Auspacken bis zu seiner Rückkehr warten müsse, er wolle dabei sein. „Das ganze Erdgeschoss auf der Keizersgracht stand voll mit Kisten, und das Auspacken geschah zum grossen Teil bei trockenem Wetter auf dem Innenhof. Beim Auspacken merkten wir erst, welch ein Reichtum da zum Vorschein kam", erinnerte sich Annie Scheltema. An Lehning schrieb Nettlau:

Wenn Sie meine Kisten auspacken, bitte ich, nichts als wertlos wegzuwerfen; es hat alles einen gewissen Sinn und Zweck, den ich erklären kannfreilich musste man ja auch den Unsinn und Unverstand schwarz auf weiss sammeln, wenn eben kein Sinn und Verstand da waren. Eine Bibliothek ist nicht jüngstes Gericht und Papierkorb, sondern eine oft interessante, oft traurige Konstatierung von Tatsachen, an denen nichts zu ändern ist. ${ }^{81}$

Winter 1937 kam Nettlau für einige Zeit in Amsterdam arbeiten. „Er war bei diesem Besuch voll Freude über seine eigene Sammlung. Wir hatten sie in drei grossen Klassenzimmern aufgestellt und nannten sie ,Sammlung Nettlau', dieser Name stand auf einer der Türen. Er sah seine ganze Sammlung zum ersten $\mathrm{Mal}$ in seinem Leben aufgestellt und zu einem grossen Teil geordnet. Er war sehr beeindruckt. Wir konnten ihm einen der Räume als Arbeitszimmer geben. Es stand da ein Schreibtisch und ein bequemer Stuhl, ich hatte ihm einen grossen Schrank für seine persönliche Arbeit freigemacht, und so konnte er da ungestört am Schreibtisch arbeiten."82 Lehning wird später sagen, dass er durch das Ordnen dieser Sammlung mehr über die Geschichte des Sozialismus gelernt habe, als auf jeder anderen Weise.

79 Bernhard Mayer, Freund und Bewunderer Kropotkins, Malatestas, Landauers und Brupbachers. Letzter machte ihn auf Nettlaus aussichtslose finanzielle Situation aufmerksam. Ausser einem monatlichen Zuschuss von dreissig Schweizer Franken stellte Mayer im August 1932 auch einen Teil seines Hauses in Ascona für Nettlaus Sammlung zur Verfügung und versorgte und finanzierte den Transport der Kisten aus Paris und London. Es ergaben sich übrigens bei dem Transport aus London überhaupt keine Schwierigkeiten; der Direktor des Chancery Lane Safe Deposit dankte Nettlau ,for your kind reference to our small services to you during the past 41 years".

80 Nettlau an Brupbacher, 16. November 1935, Archiv Brupbacher.

81 Nettlau an Lehning, 15. Dezember, Archiv Lehning.

82 Adama van Scheltema, „Herinneringen van de bibliothecaresse”, S. 149-50. 
Gewisse Facetten von Amsterdam konnten Nettlau jedoch weniger entzücken. ,Trottoir (meterbreit) und Fahrstrasse im ganz gleichen Niveau und das halbe, selbst $3 / 4$ des Trottoirs sind oft offene Kellerstiegen und selten ein Geländer. Auf der anderen Seite unzählige Radfahrer, von denen viele gern das Trottoir benutzen. Auf der Seite gegenüber ist die Gracht, der Kanal, ohne jedes Geländer und unten weder Rettungsboote, noch Stiegen, nichts." Es läge nun Schnee, aber niemand mache sich die Mühe, den Bürgersteig zu räumen. Auf keiner Wanderung im Hochgebirge wäre er so auf der Hut wie in Amsterdam. ,Trotzdem musste ich mit einem Riesensprung zwei hinter einer Ecke hervorschiessenden Radfahrern um Haaresbreite entgehen." Die Sonntagvormittage verbrachte er oft in der Bodega „,Oporto”, einer „Caféhauskirche”, wie er sie nannte, man sass da ,still lesend oder andächtig flüsternd". Nachmittags besuchte er das Rijksmuseum und wunderte sich darüber, dass jeder unter dem Museum hindurchfahren konnte, ,wodurch allmählich die Kunstwerke erschüttert und aufgelöst werden dürften". ${ }^{83}$

Im März 1938, Deutschland hatte sich Österreich bereits einverleibt, reiste Annie Scheltema mit einem Diplomatenpass nach Wien, um mit Hilfe des niederländischen Botschafters den letzten Rest von Nettlaus Sammlung zu retten, worunter die Manuskripte von Bakunin. ${ }^{84}$ Am 25. März konnte Nettlau Brupbacher berichten: „Soeben um 11, fiel mir aber ein Glückstein auf den Kopf. Die tapfere Frau hier hat alles in Wien selbst gerettet und kam soeben zurück." Er selbst hatte einen Monat vorher, am 15. Februar, Wien verlassen, um wieder in Amsterdam zu arbeiten. Er wurde von dem „Anschluss” überrascht und sollte Österreich nicht wiedersehen. Im Juli beschloss er, seinen festen Wohnsitz in Amsterdam zu nehmen. Er hielt sich gerade in der Schweiz auf, als ihm Posthumus Anfang August mitteilte, dass er ,heute Nachmittag vom Justiz-Ministerium angerufen [wurde] mit der freudigen Nachricht, dass es so gut wie sicher ist dass es Ihnen gestattet werden wird sich in Holland nieder zu lassen”. Er wäre vom Ministerium gebeten, ,Sie schon jetzt zu fragen mir mitteilen zu wollen an welchem Tag, an welcher Stunde und wo Sie die holländische Grenze zu passieren denken. Dann will das Justiz-Ministerium selbst die Grenzbeamten beauftragen Sie mit Zuvorkommenheit zu empfangen." 85

83 Nettlau an Brupbacher, 26. Januar 1937 und 27. Februar 1938, Archiv Brupbacher. In dem letzten Brief schrieb er noch einmal über die holländischen Radfahrer und Autos: „die Diktatur des radfahrenden Proletariats und der im Auto transportierten Bourgeoisie, zwei Mahlsteine, zwischen denen die sich noch mit einfachen Füssen bewegende Resten von Untermenschen wie ich, zermalmt werden."

${ }_{84}$ Vgl. Adama van Scheltema, „Herinneringen van de bibliothecaresse”, S. 151-55.

85 Posthumus an Nettlau, 5. August 1938, Archiv Nettlau. 
Nettlau war schliesslich sehr zufrieden mit dem endgültigen Resultat und betrachtete es als einen glücklichen Zufall, dass keiner seiner früheren Pläne verwirklicht worden war. ${ }^{86}$

\section{Epilog}

Bereits 1938, nach München, hatte das IISG wegen der drohenden Kriegsgefahr beschlossen, für das Material eine sichere Unterkunft in England zu suchen. ${ }^{87}$ In erster Instanz fiel die Wahl auf Harrogate (Yorkshire). Hunderte von Kisten mit Archiven, seltenen Zeitungen und Büchern (darunter auch ein Teil von Nettlaus Sammlung) wurden aus Amsterdam und Paris dorthin transportiert. Mit der Verwaltung des Materials betraut, siedelte Arthur Lehning im April 1939 nach England über. Im September erwies sich Harrogate als ungeeignet, da auch eine Abteilung der Royal Air Force dorthin verlegt wurde. Im November richtete man sich in der Banbury Road Nr 19 in Oxford ein. Ein Monat früher war das Institute of Social Studies als eine Filiale des IISG gegründet worden. Lehning war Direktor und das Vorstandmitglied Professor G. D. H. Cole vertrat den Amsterdamer Vorstand. Am 16. Mai 1940 jedoch wurde Lehning, der die deutsche Staatsbürgerschaft besass, auf der Insel Man interniert. Januar 1941 kehrte er nach Oxford zurück, wo man bereits entdeckt hatte, dass in Amsterdam für die englische Filiale keine finanziellen Vorkehrungen getroffen worden waren. Lehning war gezwungen, sich nach einem anderen Arbeitskreis umzusehen.

In Amsterdam inzwischen hatte das Institut im Juni 1940 Besuch von uniformierten Deutschen erhalten, begleitet von dem Bibliothekar des berühmten Instituts für Weltwirtschaft in Kiel, Dr Wilhelm Gülich. Am 16. Juli erging an die Sicherheitspolizei die Anweisung aus Berlin, das Institut zu schliessen, was zwei Tage später geschah. ${ }^{88}$ Posthumus protestierte hiergegen noch schriftlich bei dem Leiter des Deutschen Auslandswissenschaftlichen Instituts, Professor Franz Six, erhielt jedoch keine Antwort. Der Einsatzstab Rosenberg nahm seinen Einzug und sollte bis zum Herbst 1944 bleiben. Voll Elan wurde das Katalogisieren in Angriff

$86 \mathrm{Vgl}$. „Biographische und bibliographische Daten von Max Nettlau”, a.a.O., S. 465.

87 Aus demselben Grund wurde im April 1939 in Amboise (Loire) ein Haus gemietet, in dem ein Teil der Archive aus der Pariser Filiale untergebracht wurden. Während die Bibliothek der Filiale im Krieg verloren gehen sollte, wurden die Archive in Amboise teilweise gerettet.

88 Posthumus wusste in diesen Tagen noch ca zwanzig Kisten mit seltenen Broschüren aus dem Institut zu schaffen. Die Centrale wurde kurz darauf unter nationalsozialistische Verwaltung gestellt. Die Pariser Filiale wurde bereits am 17. Juni besetzt und 1941 ausgeplündert. 
genommen, man kaufte neue Bücher und schrieb begeisterte Berichte über diese ,marxistisch-bolschewistisch-jüdische" Sammlung. Die Bibliothek bestand damals aus ca 1200 Bücherkisten (vom Format $60 \times 60 \times 40 \mathrm{~cm}$ ) usw.; „ungefähr 18 Lastkraftwagen”, schrieb SS-Obersturmführer Prinzing am 24. August 1940 in einem Memorandum. Während der Verhöre von Posthumus, so notierte Prinzing, wurde deutlich, dass dieser ,sehr geschickt vortäuscht, dass ihn nur wissenschaftliche Interessen zu seinen Sammlungen veranlassen", weil aber die Korrespondenz nicht mehr vorhanden sei, fuhr er fort, könne man schwierig das Gegenteil beweisen. Manchmal schleichen sich kleine Versehen in den Bericht ein, so wenn Prinzing den ,anerkannt führenden Anarchisten” Nettlau August 1936 mit la Pasionaria (in Klammern wird allerdings hinzugefügt: Federica Montseny) auf Propagandatour durch ,Rotspanien” gehen lässt. ${ }^{89}$

Nach „Dolle Dinsdag”, dem 5. September 1944, wurde das ganze Institut ausgeräumt, die Besatzer zogen sich mit ihrer Kriegsbeute in die „Heimat” zurück. Im Mai 1945 fand man ein vollkommen leeres Gebäude vor. In den ersten Nachkriegsjahren wurde der grösste Teil der Sammlungen, hauptsächlich dank der nicht nachlassenden Energie Annie Scheltemas, in Deutschland zurückgefunden. In unmittelbarer Nähe der russischen Besatzungszone wurden im Mai 1946 in Windheim an der Weser zwei Schiffe entdeckt, die Alkmaar und die Komeet, in denen sich der umfangreiche Bücher- und Broschürenbestand befand; 1947 kam aus Klagenfurt der Zeitungen- und Zeitschriftenbesitz zurück. Als Gomulka 1956 in Polen an die Macht kam, wurde ein letzter Teil des im Krieg dorthin ausgelagerten Materials (23 Tonnen Dokumente, Bücher und Zeitschriften, hierunter auch Material aus Nettlaus Kollektion) zurückgegeben. Im Frühjahr 1947 wurden die Archive aus England nach Amsterdam geholt; im Herbst kehrte Arthur Lehning zurück, um die ihm 1935 übertragene Leitung der französischen und anarchistischen Abteilung des Instituts wieder aufzunehmen.

Max Nettlau war am 23. Juli 1944 in Amsterdam gestorben. Die deutsche Besatzungsmacht hatte ihn nicht behelligt. Er war ein alter Mann, hoch in den Siebzigern, der auf der Amstelkade 26 in der dritten Etage ein Zimmer bewohnte und regelmässig Annie Scheltema besuchte. Als Deutscher empfing er selbst eine Extraration. Weil man es ratsamer hielt, seinen Tod nicht bekannt zu geben,waren bei der Einäscherung nur fünf Menschen anwesend: Posthumus, Annie Scheltema, ihre Nichte Bertie Willekes-MacDonald (die spätere Frau von Boris Sapir), Werner Blu-

89 In demselben Bericht wird Lehning genannt als „wahrscheinlich Anarchist”, Nikolaevskij und Sapir als Trotzkisten, Rüter als „ein holländischer Marxist” und Annie Scheltema als ,steht auf dem äussersten linken Flügel” der SDAP! 
menberg, ein in den Niederlanden untergetauchter deutscher Sozialdemokrat und späterer Leiter der deutschen Abteilung des IISG, und Anton Bakels. ${ }^{90}$ „Professor Posthumus”, so Annie Scheltema, ,sprach sehr eindrucksvoll und sagte, dass, wenn wir uns nicht mitten im Krieg befänden, viele seinen Tod als einen unersetzlichen Verlust betrauern würden und seine Bestattung ein internationales Ereignis gewesen wäre."91 „Es war kein abenteuerliches Leben, das hier seinen Abschluss gefunden hat", schrieb Rudolf Rocker, ,,aber ein Leben voller unermüdlicher Arbeit und weitverzweigter Forschertätigkeit. Selten wurde eine so grosse Aufgabe, wie er sie sich gestellt hatte, mit so viel innerer Liebe, mit solchem Fleiss, solcher Geduld, Ausdauer und vorbildlicher Ehrlichkeit geleistet."92

\begin{abstract}
Als Bibliothekarin des IISG von 1956 bis 1973 konnte ich mich so glücklich schätzen, die Hauptpersonen dieses Artikels mit Ausnahme von Nettlau noch alle persönlich kennenzulernen: Professor Posthumus, Boris Nikolaevskij, Annie Adama van Scheltema und selbstverständlich Arthur Lehning. Max Nettlau wurde mir durch seine Werke, Briefe und die Tausende von Seiten umfassenden Erinnerungen zu einem, ,alten Bekannten”. Über das ,alte" Institut und die "grossen" Vorkriegsjahre haben mir ausser Arthur Lehning, auch Annie Scheltema und Werner Blumenberg viel erzählt. Weitere Einzelheiten erfuhr ich beim Recherchieren der benötigten Angaben für die Bearbeitung des durch das Bundesrückerstattungsgesetz vom 19. Juli 1957 ermöglichten Antrags auf Wiedergutmachung bei der Bundesrepublik Deutschland.
\end{abstract}

\footnotetext{
90 Anton Bakels (1898-1964), niederländischer Verleger und Sammler mit vielen freundschaftlichen Kontakten zu Anarchisten des In- und Auslandes. Nach dem Reichstagsbrand brachte Lehning bei ihm in Berlin die historisch wichtige Bibliothek des Londoner Arbeiterbildungsvereins in Sicherheit; sie befindet sich jetzt im IISG. In diesen Jahren bemühte sich Bakels auch um die Rettung bedrohter Revolutionäre.

${ }_{91}$ Adama van Scheltema an Mollie Steimer, 23. Juli 1945, in Rocker, Max Nettlau, S. 300.

92 Ebd., S. 305.
} 